\title{
Interactions of salivary mucins and saliva with food proteins: a review
}

\author{
Çelebiolu, Hilal Yilmaz; Lee, Seunghwan; Chronakis, loannis S.
}

Published in:

Critical Reviews in Food Science and Nutrition

Link to article, DOI:

$10.1080 / 10408398.2018 .1512950$

Publication date:

2020

Document Version

Peer reviewed version

Link back to DTU Orbit

Citation (APA):

Çelebiolu, H. Y., Lee, S., \& Chronakis, I. S. (2020). Interactions of salivary mucins and saliva with food proteins: a review. Critical Reviews in Food Science and Nutrition, 60(1), 64-83.

https://doi.org/10.1080/10408398.2018.1512950

\section{General rights}

Copyright and moral rights for the publications made accessible in the public portal are retained by the authors and/or other copyright owners and it is a condition of accessing publications that users recognise and abide by the legal requirements associated with these rights.

- Users may download and print one copy of any publication from the public portal for the purpose of private study or research.

- You may not further distribute the material or use it for any profit-making activity or commercial gain

- You may freely distribute the URL identifying the publication in the public portal

If you believe that this document breaches copyright please contact us providing details, and we will remove access to the work immediately and investigate your claim. 


\title{
Critical Reviews in Food Science and Nutrition
}

\section{Interactions of salivary mucins and saliva with food proteins: A review}

\author{
Hilal Y. Çelebioğlu, ${ }^{1}$ Seunghwan Lee ${ }^{2}$, and Ioannis S. Chronakis, ${ }^{1 *}$ \\ ${ }^{1}$ Nano-BioScience Research Group, DTU-Food, Technical University of Denmark, 2800 Kgs. Lyngby, \\ Denmark \\ ${ }^{2}$ Department of Mechanical Engineering, Technical University of Denmark, DK-2800 Kgs. Lyngby, \\ Denmark
}

*Corresponding author: Ioannis S. Chronakis, e-mail: $\underline{\text { ioach@,food.dtu.dk }}$

Keywords: $\beta$-lactoglobulin, whey, casein, gelatin, lactoferrin, lectins, emulsion 


\begin{abstract}
Mucins are long glycoprotein molecules responsible for the gel nature of the mucous layer that covers epithelial surfaces throughout the body. Mucins, as the major salivary proteins, are also important proteins for the food oral processing and digestion. The interactions of salivary mucins and saliva with several food proteins and food protein emulsions, as well as their functional properties related to the food oral processing were reviewed in this paper. The target food proteins of focus were whey proteins (lactoferrin and beta-lactoglobulin) and non-whey proteins (casein, gelatin, galectin/lectin, and proline-rich proteins). Most of the studies suggest that electrostatic attraction (between positively charged food proteins with negatively charged moieties of mucin mainly on glycosylated region of mucin) is the major mode of interaction between them. On the other hand, casein attracts the salivary proteins only via non-covalent interactions due to its naturally self-assembled micellar structure. Moreover, recent studies related to $\beta$-lactoglobulin (BLG)-mucin interactions have clarified the importance of hydrophobic as well as hydrophilic interactions, such as hydrogen bonding. Furthermore, in vitro studies between protein emulsions and saliva observed a strong aggregating effect of saliva on caseinate and whey proteins as well as on surfactant-stabilized emulsions. Besides, the sign and the density of the charge on the surface of the protein emulsion droplets contribute significantly to the behavior of the emulsion when mixed with saliva. Other studies also suggested that the interactions between saliva and whey proteins depends on the $\mathrm{pH}$ in addition to the flow rate of the saliva. Overall, the role of interactions of food proteins and food protein emulsions with mucin/saliva-proteins in the oral perception, as well as the physicochemical and structural changes of proteins were discussed.
\end{abstract}




\section{Introduction}

A mucous layer covers epithelial surfaces throughout the body and provides protection and lubrication of underlying epithelium.

The main non-water components of the mucous layer are mucins, long glycoprotein molecules that are responsible for the gel nature of the mucous layer (Efremova et al., 2002). Mucin is a glycoprotein consisting of a linear polypeptide core with a highly glycosylated central part accounting for up to $80 \%$ of its molecular weight which ranges between 0.5 and $20 \mathrm{MDa}$ (Shi et al., 2000; Bansil and Turner, 2006). Due to the abundance of negatively charged groups, arising mainly from sialic acid residues and sulphated sugars, mucins generally have low isoelectric points, estimated to be between 2 and 3. The presence of a large number of charged groups results in $\mathrm{pH}$-dependent physicochemical properties of mucins. Mucins are amphiphilic due to alternating arrays of negatively charged, hydrophilic glycosylated regions (enriched with serine, threonine, and proline residues) and hydrophobic unglycosylated patches (enriched with cysteine residues) (Fig. 1). Monomeric mucin molecules can be linked with each other, such as via disulfide bonds by cysteine residues to form larger aggregates (Durrer et al., 1995; Lee et al., 2005). Mucin's cysteine residues are capable of forming intermolecular disulfide bonds with other proteins as well (Mehrotra et al., 1998; Zalewska et al., 2000). Additionally, mucins can also form aggregates with other proteins via non-covalent interactions by involving unglycosylated regions or oligosaccharide side chains.

Furthermore, a first target for oral drug delivery is the mucus layer since it is covering the main target cells. Mucoadhesive drug delivery vehicles and methods to determine mucoadhesive properties have received considerable attention in the last two decades (Lai et al., 2009; Di Silvio et al., 2015). Mucoadhesive delivery vehicles are designed to exploit the attraction between the mucous layer and the polymer carrier of the drug delivery system. The main advantages of mucoadhesive polymer 
carriers include the localization of the carriers to a specific site within the body and the prolonged time of delivery. These features greatly enhance the bioavailability of drugs, especially for peptide and protein delivery (Peppas and Robinson 1995: Lehr, 1994). Moreover, apart from mucin's functions in biological systems, other studies have shown facile adsorption and effective lubrication on various engineering materials (Lee et al., 2005; Nikogeorgos et al., 2014; Yakubov et al., 2009).

Mucin, as the major salivary protein, is also an important protein related to the food oral processing and digestion. Through the various stages of oral processing, foods continuously mix with saliva, mucins interact with food components and the humans perceive various sensory and textural attributes. Food oral processing is a complex mechanical process including chewing, mastication, transportation and swallowing, and involves various soft and hard tissues such as palate, teeth and tongue in mouth. Therefore, it should be investigated in a step-by-step manner, starting with basic components which contribute to the oral processing. Food oral processing can be divided into three stages. The first stage of oral processing, relating to bulk properties such as hardness, brittleness, springiness of food compounds, etc., depends on their rheological properties. The last stage, relating to surface and lubrication behavior such as smoothness, slipperiness, creaminess, etc, depends on the tribological properties. Between these two stages, there is a transition stage, which is dependent on both bulk rheology and surface tribology factors, such as food thickness, consistency and creaminess. It is believed that the fundamental cause of changing sensory intensity and sensory profile is due to the rheology-tribology transition (Chen and Stokes, 2012). Tribology measurements have been developed to measure friction by mimicking the rubbing contact in oral cavity lubricated with mucin/saliva and/or food protein solution/emulsion. Sotres and Arnebrant (2013) defined the friction as the resistance offered to the sliding of one surface over another and expresses itself as a (friction) force opposing the sliding. Different factors such as adhesion, interlocking of asperities and surface deformation can also cause this resistance (Sotres and Arnebrant, 2013). To analyze the interaction 
between food and salivary components, environmental conditions, mainly temperature and $\mathrm{pH}$, are also important to consider.

Despite a number of studies addressing the interactions of mucins with polysaccharides (Menchicchi et al., 2014, 2015; Qaqish and Amiji, 1999), studies related to the interaction of mucins with food proteins are still limited (Senapati et al., 2010). Hence, in the present paper, the interactions of mucin/saliva with several food proteins and food protein emulsions as well as their functional properties related to the food oral processing are reviewed.

\section{Mucin/saliva interaction with whey proteins}

Whey proteins include $\beta$-lactoglobulin (BLG), bovine serum albumin, $\alpha$-lactalbumin, lactoferrin, and immunoglobulins. BLG represents about $50 \%$ of the total whey proteins in bovine milk. In contrast to caseins, whey proteins possess high levels of secondary, tertiary and, in most cases, quaternary structures (Edwards et al., 2009; Kinsella and Whitehead, 1989). The important functional properties of whey protein products include water binding, emulsification, foaming and whipping, gelation and nutritional properties (Singh, 2011). Emulsion-type products, e.g. coffee whiteners, whipped toppings, cream liqueurs, dietary formulations, liquid nutritional products and medical foods are an important application of caseinates and whey proteins in the food industry.

By means of trained panelists and viscosity measurements, Beecher et al. (2008) showed that electrostatic interaction between positively charged whey proteins and negatively charged saliva proteins caused astringency. Similarly, Jobstl et al. (2004) proposed that the perception of astringency is closely related with the complexation and precipitation of the astringent compounds with salivary proline-rich proteins, which increase friction in the mouth. 
Sano et al. (2005) also showed that whey protein isolate was more astringent at $\mathrm{pH} 3.5$ than gelatin based on trained panelists and taste sensors. They attributed this difference to that whey proteins are more positively charged at $\mathrm{pH} 3.5$ than gelatin. Moreover, they suggested that astringency was due to that whey proteins $(\mathrm{pH} 3.5)$ mixed with saliva $(\mathrm{pH}$ 7.0) form a slightly acidic solution ( $\mathrm{pH} 5.0)$ in which whey proteins precipitate. They have explained the formation of aggregates, as indicated by an increased turbidity of whey protein-saliva mixtures, based on two possible mechanisms. First, as proposed by Sano et al. (2005), mixing of whey proteins at acidic $\mathrm{pH}$ with saliva at neutral $\mathrm{pH}$ could result in a beverage-saliva solution at a $\mathrm{pH}$ close to the isoelectric point (pI) of whey proteins, favoring aggregation as observed by an increase in turbidity. In this case, whey protein aggregates are the main source of astringency. Alternatively, it could be due to the electrostatic interactions between the positively charged whey proteins and negatively charged saliva proteins. If salivary proteins have the PIs lower than the PIs of whey proteins, there will be a $\mathrm{pH}$ range that results in a net electrostatic attraction and aggregation. Guo et al. (2006) sequenced 5,338 distinct peptides, representing 1,381 distinct proteins, from human saliva. Approximately 3,400 of the 5,338 peptides where identified as having mean IPs lower than 5.0. These proteins are likely to be involved in the electrostatic attractions with whey proteins in acidic beverages. For example, at $\mathrm{pH} 6.8$, both the salivary and whey proteins are highly negative and they are less likely to aggregate. In contrast, at $\mathrm{pH} 3.4$, the net attraction between salivary and whey proteins appears to be the strongest, resulting in the highest level of astringency.

\subsection{Mucin interaction with Lactoferrin}


Globular proteins derived from milk are widely used as natural emulsifiers to enhance the formation and stability of oil-in-water emulsions, e.g., whey protein, BLG, $\alpha$-lactalbumin, and bovine serum albumin (Dickinson, 2003; Kralova and Sjoblom, 2009; Livney, 2010; McClements, 2004; Raikos, 2010). Recently, there has been increasing interest in utilization of lactoferrin as an emulsifier (Sarkar et al., 2009; Sarkar et al., 2010). Lactoferrin is a globular glycoprotein derived from milk and other mammalian fluids that has an unusually high isoelectric point $(\mathrm{pI}>8)$, and thus cationic at neutral $\mathrm{pH}$ whereas most other major dairy globular proteins are anionic (Steijns \& van Hooijdonk, 2000). The ability of lactoferrin to form positively charged droplets at neutral $\mathrm{pH}$ could have a number of important practical implications. Since cationic droplets do not attract positively charged transition metal ions that catalyze oxidation to the droplet surfaces, they are more stable to lipid oxidation than anionic droplets (Mei et al., 1999; Meiet al., 1998). On the other hand, cationic droplets may interact with other anionic ingredients in foods, resulting in the formation of undesirable precipitates (Guzey and McClements, 2006). They may also interact with anionic mucin molecules in the mouth causing astringency (Beecher et al., 2008; Vardhanabhuti et al., 2010).

In order to compare cationic and anionic emulsions, BLG-stabilized emulsions and lactoferrinstabilized emulsions with mucin/saliva have been investigated. When these emulsions were mixed with artificial saliva, containing a range of mucin concentrations and salts, negatively charged mucin was shown to interact more readily with the positively charged lactoferrin-stabilized emulsion droplets to provide a mucin coverage of approximately $1 \mathrm{mg} / \mathrm{m}^{2}$ (Sarkar et al. 2009). The higher mucin coverage in the lactoferrin-stabilized emulsion was attributed to the electrostatic attraction between oppositely charged mucin molecules (negative) and lactoferrin molecules (positive) adsorbed at the droplet surface. At low levels of mucin addition $(0.1-0.2 \mathrm{wt} \%)$ to the lactoferrinstabilized emulsions, the size of the droplet aggregates appeared to decrease and the emulsions appeared to be rather monodisperse at intermediate mucin concentrations $(0.5 \mathrm{wt} \%)$. However, at 
higher mucin concentrations $(2.0 \mathrm{wt} \%)$, the lactoferrin-stabilized emulsions showed aggregation of the oil droplets. To monitor the difference between anionic and cationic emulsions in the physiological condition, the mechanisms of interaction for both BLG-stabilized and lactoferrinstabilized emulsions in the presence of artificial saliva containing different levels of mucin were illustrated by Sarkar et al. (2009) (Fig. 2). Sarkar et al. (2009) suggested that lactoferrin-stabilized emulsion droplets interacted with mucin via electrostatic interactions. They showed that some bridging type flocculation occurred when there was insufficient mucin to form a complete secondary layer around the lactoferrin-stabilized droplets. On the other hand, depletion type flocculation as well as more complex aggregations involving the self-association of mucin molecules increased due to excessive mucin concentration in the continuous phase. These kinds of emulsion-saliva electrostatic interactions might occur upon consumption of emulsions in real situations and could result in different sensorial and textural perceptions in vivo (Sarkar et al. 2009; Singh and Sarkar, 2011; Singh and Ye, 2013).

In view of emulsion stability, Tokle et al. (2010) studied the effects of three anionic polysaccharides (namely low methoxyl pectin (LMP), high methoxyl pectin (HMP) and alginate) on the physicochemical properties and stability of lactoferrin-coated lipid droplets. LMP, HMP and alginate were shown to adsorb to the surfaces of lactoferrin-coated droplets at neutral $\mathrm{pH}$, which was primarily attributed to the electrostatic attraction between anionic groups on the polysaccharide molecules and cationic patches on the protein surfaces. The study by Tokle et al. (2010) further supports the electrostatic interaction between negatively charged glycosylated regions of mucin with positively charged lactoferrin. Similarly, Vardhanabhuti et al. (2010) showed that lactoferrin was astringent at pH 7.0 where no acid was added, when comparing among various whey proteins isolates (WPI) and lactoferrin at $\mathrm{pH} 3.5,4.5$, and 7.0. In contrast, astringency of all WPI decreased at $\mathrm{pH}$ 7.0. Vardhanabhuti et al. (2010) explained this as a result of that lactoferrin remained positively charged 
at $\mathrm{pH}$ 7.0. It should be noted that while lactoferrin was able to interact with negatively charged saliva proteins, the negatively charged WPI would not interact. Charge interactions were further supported by BLG or lactoferrin and salivary proteins precipitated when mixed at conditions where BLG, lactoferrin, or saliva themselves did not precipitate.

Moreover, Zhang et al. (2015) hypothesized that the presence of mucin in the simulated saliva fluids altered the charge characteristics of the protein-stabilized emulsion systems. Presumably, anionic mucin molecules adsorbed to the surfaces of cationic protein-coated lipid droplets, making the net charge negative. To support this hypothesis, they have measured the electric charge of emulsions after exposure to simulated gastric fluids with and without mucin. In the absence of mucin, the zetapotentials of emulsions stabilized by caseinate and lactoferrin were 4.5 and $5.7 \mathrm{mV}$, respectively. These results suggest that the negative charge of the protein-coated droplets observed in the stomach phase is due to adsorption of mucin molecules to their surfaces.

\subsection{Mucin/saliva interaction with $\beta$-lactoglobulin (BLG)}

$\beta$-lactoglobulin (BLG) is one of the most important and extensively studied proteins of dairy food systems. BLG is the major whey protein constituting $>50 \%$ of the total whey proteins in bovine milk. BLG is a typical globular protein with molecular weight of $18.3 \mathrm{kDa}$ and a radius of approximately $2 \mathrm{~nm}$ (Zúniga et al., 2010). According to its amino acid sequence and three-dimensional structure, BLG belongs to the lipocalin family, which can bind to small hydrophobic ligands and may thus act as specific transporters (Kontopidis et al., 2004). It is a predominantly $\beta$-sheet protein. The $\beta$-barrel, or so-called calyx, is conical and is made of two $\beta$-sheets: the B-D strands and N-terminal half of the A strand (denoted $\mathrm{AN}$ ) form one sheet, and the $\mathrm{E}-\mathrm{H}$ strands and $\mathrm{C}$-terminal half of the A strand (denoted AC) form the other (Fig. 3). On the outer surface of the $\beta$-barrel, between the $\mathrm{G}$ and $\mathrm{H}$ 
strands, is the 3-turn $\alpha$-helix. The loops that connect the $\beta$-strands at the closed end of the calyx, BC, $\mathrm{DE}$, and FG, are generally quite short, whereas those at the open end, $\mathrm{AB}, \mathrm{CD}, \mathrm{EF}$, and $\mathrm{GH}$, are significantly longer and more flexible (Brownlow et al., 1997). In the calyx, there is a large central cavity which is surrounded by hydrophobic residues and is accessible to solvent. This cavity provides the principal ligand-binding site. BLG contains two tryptophan residues, Trp 19 on the A strand and Trp 61 on the $\mathrm{C}$ strand. The former is buried in the hydrophobic core whereas the latter is exposed to the solvent in the native structure, making them useful probes for monitoring site-specific conformational changes. BLG contains many charged groups and its structure and properties therefore depend strongly on the $\mathrm{pH}$ and ionic strength (Fang and Dalgleish, 1997). Taulier and Chalikian (2001) addressed six pH-dependent structural states of BLG depending on solution conditions, and characterized the acid- and base-induced conformational transitions between these structural states over the $\mathrm{pH}$ range from 1 to 13 . This $\mathrm{pH}$-dependent system may indicate that one of BLG functions is to bind to non-polar molecules and transport them through the acidic environment (stomach) into the basic environment (intestine). This strong $\mathrm{pH}$ dependency suggests that electrostatic interactions could play a significant role in the interactions of BLG with other molecules. The electrostatic attractions even enhance the protein aggregation due to BLG-BLG interaction (Majhi et al., 2006). An association between peptides and BLG due to electrostatic attraction was recently observed in the study of Kosters et al. (2013). They have also observed stronger binding or even the formation of a covalent interaction between the free sulfhydryl group of the peptides and a cysteine residue of the BLG.

The three-dimensional structure of a protein may facilitate interactions with other components found in foods or the gastrointestinal (GI) tract lumen, thus altering their stability to proteolysis which is related with gastric digestion (Moreno et al., 2005). It has been also reported that the effects of 
physiological surfactants on the simulated GI proteolysis of bovine BLG, showing that under certain conditions BLG is almost completely protected from simulated digestion (Mandalari et al., 2009).

BLG is critical protein for the nutritional intake during digestion, as well as for a successful manipulation of the physical and sensorial attributes of colloidal food systems (such as emulsion stability, creaminess and rate of flavor release). However, both emulsions and saliva are complex systems. For instance, human saliva consists mainly of water $(99.5 \%)$, various proteins $(0.3 \%)$, small organic compounds and inorganic salts and has a pH of around 6.8 (Zalewska et al., 2000). Therefore, many scientists preferred to focus on the major protein component of saliva, highly-glycosylated mucin, and its interaction with various food proteins used as emulsifier in order to understand proteinprotein interaction mechanisms and the effect of protein charge on the emulsion-saliva interaction. Thus, one of the most commonly used proteins to investigate the interaction with saliva/mucin is BLG.

\subsubsection{Saliva interaction with BLG}

Kelly et al. (2010) studied the interaction between BLG and salivary proteins and investigated the effects of protein concentration on astringency. Due to the high number of samples, they divided sensory evaluation into three studies. The first study investigated the effect of protein concentrations ranging from 0.25 to $4 \%$. Protein concentrations in the second study ranged from 4 to $13 \%$. In the third study, samples were selected to cover the whole range of concentrations, and time-intensity analysis was chosen to provide more comprehensive data (i.e., time to reach maximum astringency, astringency duration). They found that the changes in the astringency by varying the concentration of protein are dependent on $\mathrm{pH}$. At $\mathrm{pH} 3.5$, astringency was significantly increased in the protein concentration range from 0.25 to $4 \%(w t / w t)$ and then remained constant from 4 to $13 \%$ (wt/wt). In 
contrast, at $\mathrm{pH} 2.6$, astringency was decreased with an increase in protein concentration $[0.5-10 \%$ $(\mathrm{wt} / \mathrm{wt})]$. This suggests a complex relationship that includes $\mathrm{pH}$ and buffering capacity of the beverages. Furthermore, saliva flow rates increased with increasing protein concentrations, showing that the physiological conditions in the mouth changed with the protein concentration. Maximum turbidity of whey protein-saliva mixtures was observed between $\mathrm{pH} 4.6$ and 5.2. Both sensory evaluation and in vitro study of the interactions between BLG and saliva indicate that the astringency of whey proteins is a complex process determined by the extent of aggregation occurring in the mouth, which depends on the $\mathrm{pH}$ of the whey protein beverage and buffering capacity in addition to the flow rate of the saliva. This trend was not same with the study of Beecher et al. (2008) in which maximum astringency was found at $\mathrm{pH} 3.4$ and a decrease in astringency was observed when the $\mathrm{pH}$ was lowered to 2.6. The difference may be due to the type of protein used and the processing parameters. Beecher et al. (2008) used whey protein isolates $(6 \%(\mathrm{wt} / \mathrm{vol})$ protein $)$ and heated the whey protein beverages. Meanwhile, Kelly et al. (2010) used BLG because of its higher purity and the samples were unheated to reduce the degree of protein aggregation. These factors may have contributed to the different results.

Peak turbidities resulting from polyphenols and mucin interactions were correlated with maximum astringency (Monteleone et al., 2004; Condelli et al., 2006). Nevertheless, such a linear correlation with protein-based astringency was not observed by Kelly et al. (2010), who explained this by the differences between intermolecular binding mechanisms of proteins and polyphenols. Interactions between polyphenols and salivary proteins are a result of hydrogen bonding (Haslam, 1974) or hydrophobic interactions (Hagerman and Butler, 1980). These interactions have minor $\mathrm{pH}$ dependence. In contrast, as protein charge is $\mathrm{pH}$ dependent, interactions between saliva and whey proteins will be also pH dependent. Thus, Kelly et al. (2010) suggested a dynamic model to explain 
the astringency of proteins as $\mathrm{pH}$ would depend on the amounts and buffering capacities of saliva and protein beverage, coupled with changes in saliva flow.

Vardhanabhuti et al. (2011) investigated the perception of astringency in relation to the effect of BLG at $\mathrm{pH} 3.5$ and 7.0 by studying the lubrication properties of saliva using a tribological approach. They have used fresh stimulated whole saliva without any treatment in all experiments. Saliva was adsorbed onto surfaces of a rotating poly(dimethylsiloxane) (PDMS) ball and disc to form a film under conditions that mimic the rubbing contacts in the oral cavity (Bongaerts et al., 2007) and the lubricity of saliva films upon exposure to astringent compounds was measured. While addition of nonastringent BLG at $\mathrm{pH} 7.0$ slowly increased the friction of saliva films between tribopair surfaces, BLG at pH 3.5 rapidly increased the friction coefficients of saliva, similar to other astringent compounds (e.g. epigallocatechin gallate and alum). This supports the hypothesis that astringency of BLG is closely associated with the loss of lubricating properties of saliva, which is in agreement with the well-accepted astringency model of polyphenols. They concluded that aggregation and/or precipitation of whey proteins at their pI's, as well as charged interactions between whey proteins and salivary proteins, can contribute to the astringency of whey proteins at low $\mathrm{pH}$. A number of studies already provided evidences that support the role of electrostatic interactions in milk protein astringency (Malone et al., 2003; Vardhanabhuti and Foegeding, 2010; Vardhanabhuti et al., 2010). An outstanding significance of the study by Vardnahabhuti et al. (2011) is that it showed that these interactions lead to the loss of lubricating properties of saliva. Increasing BLG concentration at $\mathrm{pH}$ $3.5(0.5-10 \% \mathrm{w} / \mathrm{w})$ caused a rapid increase in friction coefficient; however, at the highest protein concentration, the friction coefficient was lower than the values observed for the lower protein concentrations, although it was still higher than the values observed from water. This clearly supports the hypothesis that precipitation of whey proteins from mixing with saliva or interaction between positively charged whey proteins and salivary proteins leads to an increase in friction and/or the loss 
of saliva lubrication, and thus contributes to astringency of whey proteins at low $\mathrm{pH}$. Additionally, Vardhanabhuti et al. (2011) suggested that static tribology testing is different from the dynamic inmouth system such that a simple relationship between friction and sensory astringency cannot be found for all conditions. This is due to the complexity of the dynamic saliva model and whey proteins, in addition to the variety of parameters such as concentration, $\mathrm{pH}$, heat, and surface properties that effect the friction. Overall, using tribology to study the lubrication properties between saliva or saliva proteins with food proteins is a valuable approach to study the perception of astringency.

\subsubsection{Mucin interaction with BLG}

Recently, our group has focused on the interactions of bovine submaxillary mucin (BSM) with BLG at different $\mathrm{pH}$ values in order to understand the protein-protein interactions in a food-saliva model system. Among several mucin types involved, submaxillary mucin is the one most related to oral processing. In order to establish a basis to understand food oral processing of the two proteins on the molecular level, the ratio of 1:1 was selected. Dynamic light scattering (DLS) was employed to investigate the changes in hydrodynamic radius of proteins. High and low field Nuclear Magnetic Resonance (NMR) techniques were employed to characterize the interaction by monitoring changes on the chemical shifts of proteins residues. Finally, secondary and tertiary structures of proteins were studied using circular dichroism (CD) spectroscopy (Çelebioğlu et al., 2015). The zeta potentials of the proteins showed that the surface charge characteristics of the BLG-BSM mixture were dominated by the BSM. Results from DLS measurements suggested that the interaction between the proteins caused a more compact conformation of BSM as the BLG integrated into the BSM. Far UV and near UV CD spectroscopy studies of the mixture of the two proteins showed intermediate spectra compared to each protein alone for both secondary and tertiary structure of the proteins, which may 
support the proposed interaction between them. High field NMR measurements are consistent with polar interactions at $\mathrm{pH} 5$ and $\mathrm{pH} 3$, whereas no significant interaction was detected at $\mathrm{pH}$ 7.4. Longer $\mathrm{T}_{2}$ relation times were observed for the BLG-BSM mixture, especially at acidic $\mathrm{pH}$, which was attributed to higher water mobility. The higher water mobility may indicate that fewer charged groups on the proteins surfaces were available for protein-water interaction due to the interactions between the hydrophilic parts of BLG and BSM compared to BSM alone. The overall conclusion is that the higher hydrophilic interaction between the proteins at lower $\mathrm{pH}$ supported the $\mathrm{pH}$ dependent activity of both BLG and BSM. Furthermore, the positively charged groups of BLG, especially at acidic pHs, neutralized negatively charged groups of BSM and caused the BSM to coil or contract into a smaller hydrodynamic volume (Fig. 4), as suggested by Shrivastava and Nair (2003) as well. In fact, even a weak hydrogen bonding between BLG and BSM brings about aggregation of mucins into a more compact structure at $\mathrm{pH}$ 7.4. The NMR results also implied that negatively charged BLG has a tendency to interact with negatively charged mucin via secondary interactions (hydrogen bonding and hydrophobic effects), where the electrostatic interactions are unlikely to be the main reason of the binding.

Since BSM and BLG showed an interesting interaction, the interfacial properties of BLG, BSM, and their mixtures at air/liquid interface also draw attention. It is important to understand the interfacial rheological properties of adsorbed BLG and mucin layers and their network formation at the liquid surface that are relevant in a wide range of applications such as foam and emulsion stability or multiphase fluids processing. The interfacial rheological properties of solutions of BLG (as a model

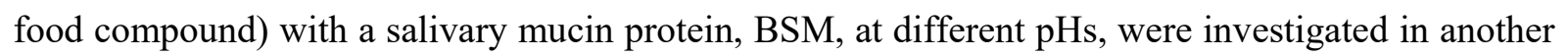
recent study by the authors (Çelebioğlu et al., 2017). The results showed that all protein layers (BSM, BLG, and BLG-BSM mixtures) formed at air/water interface has some similarities such as a rapidly developed elastic interfacial network, low frequency dependence of the interfacial modulus. The high 
molecular weight BSM formed a weak viscoelastic interfacial network (lower modulus) compared to BLG at all $\mathrm{pHs}$, which is destroyed even at low strain $(0.003 \%)$. The $\mathrm{pH}$ has a significant effect on the surface density of adsorbed BLG proteins, as it determines the net charges and the modulus of the interfacial network. At $\mathrm{pH}$ close to $\mathrm{pI}$, electrostatic repulsions between the adsorbed BLG molecules are minimized at the interface, and it promotes the formation of stable adsorbed layer with a high elastic modulus. Furthermore, BLG molecules move faster due to their smaller size/mass than mucins, and dominate the surface adsorption and the network formation for the BLG-BSM mixtures. However, BLG-BSM protein mixtures exhibited interfacial properties with lower elastic and viscous moduli than BLG, as a result of competitive displacement of BLG proteins with BSM molecules from the interface. We propose that BSMs decreased the surface viscoelasticity and the rigidity of the BLG layers through the penetration of the hydrophobic parts of BSM between the adsorbed BLG molecules and disrupt their cohesive assembly, which was most pronounced at pH 5 (Fig. 5). Moreover, it is important to stress that facile attraction of BSM molecules towards BLG layer within water phase is not sufficient to activate this mechanism. At $\mathrm{pH} 3$, for example, despite electrostatic attraction between oppositely charged BSMs and BLG layer, the reduction in viscoelasticity and rigidity is weaker compared to that at $\mathrm{pH}$. This can be explained by that overall hydrophilic nature of the interaction between them hinders the hydrophobic parts of BSM to disrupt the assembled layer of BLG and extend its interaction with air.

We have also studied the surface adsorption of BLG, BSM and their mixture at the solid/liquid interface (Çelebioğlu et al. 2016). The study based on bicinchoninic acid (BCA) protein qualification assay showed that mucins were not only higher than BLG in the adsorbed amount (masses) onto the solid hydrophobic surface, but also adsorb in a more compact conformation due to a high flexibility to accommodate themselves in a narrow space and/or a possibility to form multilayers (Çelebioğlu et al. 2016). However, BLG can readily dominate the initial stage of surface adsorption at the solid/water 
interface in the mixture solution of BSM and BLG due to the ability of the smaller and lighter BLG molecules to reach the surface faster than BSM. In the adsorption of the BLG-BSM mixture onto hydrophobic solid surfaces, it was assumed that there is a large portion of "free" BLG molecules in the mixed protein solutions, and that they participate in the surface adsorption process in competition with BSM. In addition to BSM, PGM was also used for interaction studies with BLG. The fact that both mucins are highly relevant to food digestion process, yet to different organs, is the first motivation to compare them. Additionally, in parallel with common structural features of the two mucins (Bansil et al., 1995; Sandberg et al., 2009), reported differences in their biophysical properties, especially the lubricating properties (Lee et al., 2005; Nikogeorgos et al., 2014), may lead to different interaction with BLG and alteration in the lubricating properties. The surface adsorption results showed that the net effect of mixing BLG and PGM is featured with substantially decreased adsorbed masses compared to the neat PGM solutions. Thus, it was suggested that BLG dominates also the solid/water interface for BLG-PGM mixture.

Another novel approach was to apply tribological techniques to investigate the interaction of BLG with mucins and investigate how it affects their lubricating properties (Çelebioğlu et al. 2016). Recently, tribology has emerged as a new instrumental approach to investigate oral processing of food emulsions in simulated oral environment (Meyer et al., 2011; Vardhanabhutiet al., 2011; Chojnicka- Paszun et al., 2012; Chen and Stokes, 2012; Van Aken, 2013; Selway and Stokes, 2013; Prakash et al., 2013; Chen et al., 2014; Joyner Melito et al., 2014). In turn, this is often correlated with food's sensory perception (Meyer et al. 2011; Vardhanabhuti et al. 2011; Chojnicka-Paszun et al., 2012; Selway and Stokes, 2013; Prakash et al., 2013). Tribology is particularly useful for understanding the behavior of thin films formed between two opposing surfaces where rheological and structural/mechanical properties of food may no longer explain their behavior sufficiently. Recent applications of tribological techniques allowed for quantitative characterization of the lubricating 
properties of the fluids involving saliva and BLG or other astringents. For example, Vardhanabhuti et al. (2011) showed that addition of BLG into a soft tribological interface increased the interfacial friction forces, yet at varying rates depending on $\mathrm{pH}$. Aggregation of macromolecules (BLG) with hydrogel (saliva) is, however, a complex process influenced by a number of parameters.

Recently, we have investigated the molecular-level interaction between mucins and BLG by means of tribological approaches according to mucin type, solution $\mathrm{pH}$, and protein concentration. Hydrophobic interfaces, namely PDMS-PDMS and polyoxymethylene (POM)-PDMS, were employed for feasible adsorption of the proteins and consequent possibility of assessment of the boundary lubricating properties. The structural and mechanical properties of thin films generated from two types of mucins, namely, BSM and PGM in aqueous environment, were also investigated by Madsen et al. (2016) who showed that both mucins generated hydrated films on hydrophobic PDMS surfaces from spontaneous adsorption arising from their amphiphilic characteristic.

Overall, we have observed that mucins have effective lubricating properties, in particular BSM, compared to BLG. Nevertheless, nearly ignorable lubricating effect by PGM, despite its facile surface adsorption, suggests that other parameters than adsorbed masses play a significant role to impart superior lubricity of BSM to PGM or BLG (Fig. 6). While both pin-on-disk tribometry and minitraction machine (MTM) were employed to provide the tribological contacts with different contact pressure, speed range, and slide/roll ratio, the dominating lubrication mechanism by the protein solution was boundary lubrication. Surface adsorption and lubricating properties of mixed protein solutions, such as BLG-BSM and BLG-PGM, with respect to neat protein solutions were of prime interest as it can be compared with the well-known role of BLG as astringency to form a complex with saliva and rapidly deplete from the tribological interface at acidic $\mathrm{pH}$ (3.5, for example). Even in the absence of tribostress, the adsorbed masses of the mixed protein solutions reduced significantly, and BLG appeared to dominate the surface adsorption event, presumably due to the reduced 
concentration of mucins as well as the Vroman effect. Nevertheless, excellent lubricity was still observed at $\mathrm{pH} 7.4$ and BSM apparently dominated the tribological interface, which highlights the excellent lubricating capabilities of BSM. Although being still relatively more lubricious than the other proteins, the BLG-BSM mixture showed the highest level of degradation in the lubricity of $\mathrm{BSM}$ at $\mathrm{pH}$ 5, which contrasts the case of BLG-saliva interaction. This is due to that instead of strong aggregation, as in BLG-saliva, the lubricating properties of BLG-BSM are determined by competitive adsorption of the two proteins onto substrates. Most importantly, these observations further suggest that BLG and BSM molecules do not form strong aggregates, especially under tribological stress. PGM's intrinsically weaker lubricity remained largely unchanged even in the interaction with BLG.

Consequently, mucins and BLG showed an interesting interaction and different surface adsorption behavior at solid/liquid or liquid/air interfaces. However, little has been known about the hydrophobic interaction between the BLG and mucins, and the role of hydrophobic residues of these proteins to date.

\subsection{Mucin/saliva interaction with whey protein stabilized emulsion}

Due to their emulsifying property, proteins found in milk or in other foods frequently used in foodemulsions-systems. Thus, studies of the mucin/saliva interactions with well-ordered protein stabilized emulsions are very close to defining the behavior of real food products. An understanding of the oral processing of an emulsion is critical for a successful manipulation of the physical and sensorial attributes of colloidal food systems, such as emulsion stability, creaminess and rate of flavor release. Food emulsions are exposed to a range of processing steps during oral consumption such as mixing with saliva, heating or cooling to the body temperature. In addition, air is introduced, and the 
emulsions come into contact with oral surfaces and are exposed to complicated saliva flow profiles. It is anticipated that saliva-emulsion interactions play an important role in understanding emulsion perception, however, little is known about the oral behavior of food emulsions (Aken et al., 2007). Previous studies dealing with the interaction between emulsions and saliva was focused on, firstly, sensory analysis of emulsions in relation to the saliva flow (Engelen et al., 2003) and composition (Engelen et al., 2007), and secondly on the physicochemical properties of emulsions in vitro (BarylkoPikielna et al., 1994; Kilcast and Clegg, 2002; Metcalf and Vickers, 2002; de Wijk et al., 2003). Then, the flavor release from emulsions (de Roos, 2003) as measured in mouth models (Doyen et al., 2001; van Ruth et al., 2002; van Ruth and Roozen, 2000a,b) and in vivo via e.g. electronic noses (Miettinen et al., 2002) are other subjects of studies.

van Aken et al. (2003) reported a strong aggregating effect of saliva on both proteins (milk protein including caseinate and whey protein) and surfactant-stabilized emulsions. In addition, explorative experiments were carried out to gain insight into the oral behavior of commercial emulsions (van Aken et al., 2007). They have further investigated the aggregation phenomena to elucidate the physicochemical effects of saliva on protein-stabilized food emulsions, with an emphasis on the role of high molecular weight mucins. They observed that mixing emulsions with saliva or mucin can induce droplet aggregation and suggested that the observed behavior affects the texture and rheological properties of emulsions and thus the sensory perception of emulsions. For instance, salivainduced droplet flocculation leads to an increase in low-shear viscosity, which is related to product viscosity with mouthfeel (van Aken et al., 2007).

The high molecular weight salivary mucin was also modeled by porcine gastric mucin (PGM), which consists of both MUC5AC and MUC6 (Nordman et al., 2002). MUC5AC has particularly large similarities to the high molecular weight human salivary mucins (MUC5B) (van Klinken et al., 1998; Offner et al., 1998). In the study of Vingerhoeds et al. (2005), the rheological behavior of whey 
protein isolate (WPI) emulsions upon addition of PGM was determined. Aggregation of the emulsions was clearly observed and the results suggested that mucin, as the main component in saliva, is responsible for the observed aggregation, but also indicated that other salivary components could play a role. They have observed a reversible aggregation upon dilution with water, indicating that the bonds between the emulsion droplets were relatively weak and coalescence was negligible. Hence, they concluded that the aggregation might not be due to covalent bonds or to a precipitation mechanism such as an antigenic reaction. The particle size of the emulsions was not altered by the addition of PGM, meaning that droplet flocculation can arise from depletion or a bridging mechanism (Blijdenstein, Hendriks et al., 2003; Blijdenstein, van Vliet et al., 2003; Dickinson and Pawlowsky, 1997). The mechanism of droplet flocculation was determined by the nature of the interaction between the surfactants and the polymers. For instance, in the absence of the interaction between surfactants and polymers, emulsion droplets can lead to depletion flocculation. On the other hand, under attractive interactions between them, emulsion droplets can impose bridging flocculation (Healy and Lamer, 1964). To elucidate the mechanism behind the observed mucin-induced aggregation, Vingerhoeds et al. (2005) performed de-mixing experiments as a function of the concentration of PGM. Removal of excess BLG by washing the emulsion before mixing with PGM had no effect on the occurrence of flocculation as observed by light microscopy. This indicates that the dissolved protein emulsifier is not involved in the flocculation. Overall, those observations are indicative of that depletion flocculation is the leading mechanism in the case of mucin/saliva interaction with protein-stabilized emulsion.

\subsection{Mucin/saliva interactions with BLG-stabilized emulsion}


Since BLG dominates the total whey protein content $(>50 \%)$ and has good emulsifying properties, most studies have focused on mucin/saliva interactions with BLG-stabilized emulsions. Using this approach a simplified model of oral processing of real foods with saliva can be established. Various attempts have been reported in literature to explore the effect of mixing saliva/mucin with the milk proteins, especially by using the BLG-stabilized emulsions (Sarkar et al., 2009; Sarkar et al., 2010; Silletti et al., 2007; Vingerhoeds et al., 2005). Sarkar et al. (2009) determined the physicochemical effects of the porcine gastric mucin (Sigma, Type II) on negatively charged BLG-stabilized emulsion. They showed that the BLG-stabilized emulsions remained homogeneous in the presence of mucin at low concentrations. However, the emulsions showed network-like flocculation by addition of mucin at the concentration of $1.0 \mathrm{wt} \%$. These emulsion-saliva mixtures (containing added $1.0 \mathrm{wt} \%$ mucin) reverted back to homogenous dispersions after dilution with water, which indicated that the flocculation was reversible. Moreover, Sarkar et al. (2009) mentioned that for the BLG-coated droplets, the presence of some positive patches along the adsorbed BLG molecules probably resulted in electrostatic interactions with the negatively charged mucin molecules. Moreover, there is also possibility of hydrophobic interaction between unfolded BLG and mucin molecules at the adsorbed layer at low ionic strengths of artificial saliva.

Silletti et al. (2007) also hypothesized that depletion flocculation was responsible for the observed flocculation. To further unravel the mechanism, they investigated the role of electrostatics on the behavior of emulsion/saliva mixtures. Emulsions stabilized with differently charged surfactants and proteins were mixed with saliva. Strongly negatively charged emulsions (SDS and Panodan) did not flocculate, and this could be due to the electrostatic repulsion between the droplets overcoming the attractive depletion and van der Waals interactions. However, reversible flocculation was observed for neutral and weakly negatively charged emulsions (Tween 20 and BLG pH 6.7). Silletti et al. (2007) suggested that this is probably due to depletion interactions, induced by large salivary protein 
like mucins, in combination with the van der Waals interactions and the sufficiently low electrostatic repulsion between the droplets. Positively charged emulsions (e.g. CTAB, lysozyme and BLG at pH 3.0) showed irreversible flocculation, leading to rapid phase separation. These findings point to a role of electrostatic attraction between the negatively charged proteins present in saliva and the positively charged surfaces of the emulsion droplets. Certainly, these results indicate that the sign and the density of the charge on the surface of the droplets contribute significantly to the behavior of an emulsion when mixed with saliva. Depending on the charge, saliva-induced emulsion flocculation is driven by two different main mechanisms: depletion flocculation and electrostatic attraction.

By employing mucin and BLG-stabilized emulsions, Silletti et al. (2010) investigated the interactions between BLG-stabilized emulsion droplets and salivary proteins (mucin), by means of different techniques, e.g. infrared spectroscopy, Western blotting, PAS staining and SDS-PAGE coupled to MS. They showed that adsorption/association of mucin onto the emulsion droplets is related to the type of emulsifying proteins at the oil-water interfaces and it is driven by the overall net charge at the droplet's oil-water interfaces, i.e. negative for BLG-stabilized emulsion at neutral pH. Sarkar et al. (2010) also mentioned that the presence of a low level of mucin appears to promote the flocculation of BLG-stabilised emulsions, possibly through a bridging mechanism. Broadly, neutral and negatively charged emulsions undergo reversible depletion flocculation whereas cationic emulsions show irreversible associative electrostatic interactions with mucin and salivary salts. Similarly, Teng et al. (2016) found that cationic polymers interact readily with mucin and exhibited better mucoadhesion properties than unmodified BLG. Moreover, Singh and Ye (2013) showed depletion flocculation of a BLG-stabilized emulsion (20 wt $\%$ soybean oil, $1.0 \mathrm{wt} \%$ BLG) when mixed with an artificial saliva composition containing PGM. This flocculation was largely dependent on the mucin concentration (a critical mucin concentration of $0.4 \mathrm{wt} \%$ ) present in the saliva. Thus, the differences found between negatively charged and cationic emulsions signify the importance of the surface 
charges on the interaction/flocculation observed in the presence of saliva/mucin. Moreover, the effect of mucin concentration on emulsion flocculation (of similar-surface-charged-emulsions) may also further indicate the importance of surface hydrophobic interaction.

\section{Mucin/saliva interaction with non-whey proteins}

\subsection{Mucin/saliva interaction with Casein}

Caseins evolve from members of a group of secreted calcium (phosphate)-binding phosphoproteins (Kawasaki and Weiss, 2003; Rijnkels et al., 2003; Kawasaki et al., 2004, 2011; Lemay et al., 2009). In eutherian milks, at least three and normally four gene products of casein $(\mathrm{CN})$ are found; namely, $\alpha \mathrm{S} 1-, \alpha \mathrm{S} 2-, \beta-$, and $\kappa-\mathrm{CN}$, but in some species two quite different $\alpha \mathrm{S} 2-\mathrm{CN}$-like genes are active, raising the total number of gene products to as many as five. (Holt et al. 2013).

Caseins constitute about $80 \%$ of the proteins of bovine milk and they contain high numbers of proline residues evenly distributed throughout their amino acid sequences and have relatively open structural features (like the salivary proline-rich proteins). For this reason, isolated caseins have often been used as model proteins in various polyphenol-protein studies (Jobstyl et al., 2004; Pascal et al., 2008; Yan et al., 2009).

Withers et al. (2013) recently investigated the potential adhesion of milk proteins to porcine oral mucosa in vitro. This study aimed to evaluate the retention of milk proteins (casein and BLG) on the oral epithelial surfaces including buccal and tongue tissues. The hypothesis of this study was that the adhesion of milk proteins to the oral epithelium may be related to the mouth drying in dairy products. Purified casein and BLG were fluorescently-labelled, placed on porcine oral mucosal tissues and their 
resistance to wash out with simulated saliva was monitored using fluorescence microscopy (Fig. 7). Fluorescein isothiocyanate (FITC)-dextran was used as a negative control in these experiments because it is not expected to provide substantial retention effects as a non-ionic, poorly mucoadhesive polymer. Unlabeled samples showed no fluorescence at this wavelength, indicating that no intrinsic fluorescence would be demonstrated by the proteins alone. Therefore, all fluorescence observed originated from the FITC-bound proteins with casein exhibiting greater fluorescence than BLG in this study. Dynamic light scattering indicated that the labelling process did not destroy the micellar structure of casein in solution. The presence of BLG on the mucosal surface was detected even after 30 washes, which confirms its stronger ability to adhere to buccal membrane compared to FITCdextran. Thus, Withers et al. (2013) suggested that although BLG interacted with the cheek mucosal surface, the salivary washes were able to remove this protein eventually. Casein was found to remain on the mucosal surface in substantial quantities even after 50 washes, indicating that this protein also strongly interacts with mucosal surface. Moreover, thiol content measurements showed that the level of thiols in BLG was found to be significantly higher than in casein $(p<0.001)$. Both casein and BLG were found to be negatively charged at $\mathrm{pH} 9.0$ as expected. The greater zeta-potential of BLG implies a greater stability of the protein in solution, relative to casein. On the other hand, the viscosity of casein solution was 2.3 times higher than BLG, which is likely related to the ability of casein to form naturally self-assembled micellar structures (Hagerstrom and Edsman, 2003). Overall, the results supported that the interaction between mucin present in the saliva with BLG, but not with casein. This may be a result of the markedly different rheological properties of casein, in part a result of its micellar nature (Withers et al. 2013). In addition, Withers et al. (2013) proposed that electrostatic interactions are unlikely to be the main cause of mucoadhesion because both proteins are overall negatively charged under the near-neutral $\mathrm{pH}$ of the oral cavity. However, compared to BLG, the less 
negatively charged casein should feel a weaker repulsion from the negatively charged mucosal surface.

Another recent study by Withers et al. (2014) aimed to test the hypothesis that casein within proteinfortified beverages at neutral $\mathrm{pH}$ could contribute to perceived mouth drying. Sequential profiling found that the whey protein concentrate (WPC75; containing 75\% wt/wt protein) and sodium caseinate (NaCas; containing $85 \% \mathrm{wt} / \mathrm{wt}$ protein) samples were not significantly different for mouth drying or chalkiness. Previously, it was suggested by several authors that mouth drying was an attribute found to build substantially during the consumption of oral nutritional supplement (ONS) dairy-based beverages, and it could originate from whey or casein sources (Methven et al., 2010). Previously, whey-based dairy beverages have found to be astringent, especially at reduced pHs; it has been proposed that the negatively charged salivary proteins bind electrostatically to positively charged whey proteins to precipitate around the oral cavity (Sano et al., 2005; Ye et al., 2011) or bind to oral epithelial cells (Ye et al., 2012). Similarly, Withers et al. (2014) found that ONS mouth drying appears to originate predominantly from whey proteins, and that masking mouth drying is not a simple task. However, the potential for casein to contribute to mouth drying was also demonstrated. Whether casein-derived mouth drying is due to the presence of $\gamma-\mathrm{CN}$ remains unanswered, and further investigation, including the use of HPLC to quantify $\gamma-\mathrm{CN}$ in heat-treated, protein-fortified beverages over shelf life, was recommended.

In a different point of view, Hug et al. (2016) also studied the interaction between casein and saliva using adhesion, SDS-PAGE, and ELISA techniques. Their aim was to demonstrate the repair of early dental caries lesions by the application of the remineralisation technology based on casein phosphopeptide-stabilised amorphous calcium phosphate complexes (CPP-ACP). Hug et al. (2016) showed that the two predominant peptides of the casein phosphopeptide (CPP) have the ability to interact with selected salivary proteins and peptides found as components of the enamel pellicle. The 
sequences of both $\alpha \mathrm{S} 1-\mathrm{CN}(59-79)$ and $\beta-\mathrm{CN}(1-25)$ peptides have hydrophobic and hydrophilic regions. This enables them to bind to a range of proteins through hydrophobic or electrostatic interactions. Nevertheless, it is evident that the CPP are not promiscuous binders of salivary proteins, but display selectivity (Hug et al. 2016). After all, they attributed the non-covalent interactions between specific salivary proteins and peptides and the CPP, to the concomitant retention of mineral ions and peptides derived from the $\mathrm{CPP}-\mathrm{ACP}$ complexes within plaque on the enamel surface. In summary, Hug et al. (2016) elucidated the mechanism of anticariogenicity displayed by the CPPACP nanocomplexes involving several molecular interactions between organic and inorganic molecules. These interactions include the binding of the CPP to specific salivary proteins and peptides.

Overall, the above studies propose that casein attracts the salivary proteins only via non-covalent interactions due to its naturally self-assembled micellar structure. The binding of casein to salivary proteins is weak, however, some predominant peptides of casein display selective binding. Moreover, casein is able to interact with mucosal surface and this interaction is stronger than the casein-mucin interaction. Nevertheless, different species of casein or different casein complexes may show different mucoadhesion and interaction properties with the salivary proteins. It is to note that in contrast, BLG shows significant hydrogen binding and hydrophobic attraction to mucin while the electrostatic attraction is less pronounced. Hence, further studies are needed in order to assess the interaction mechanisms of casein with salivary proteins, by using different casein species with different charges and protein content, with variable mucosal surfaces.

\subsection{Mucin/saliva interaction with gelatin}


Gelatin, one of the most commonly used hydrocolloids in the food products, is commercially derived from collagen extracted from the bone, skin or tendons of animals. It contains glycine, proline and hydroxyproline, and is used as a thickening agent in dessert jellies, confectionery jellies and gums (Johnston-Banks, 1990). Gelatin is also used as mucoadhesive materials due to its ability to adhere to the mucus layer and release the loaded drug in a sustained manner. Wang et al. (2000) demonstrated that aminated gelatin microspheres, with high primary amino group content, showed a sustained amoxicillin release characteristic and a considerable gastric mucoadhesive property in vitro. Mucoadhesion involves different kinds of interaction forces between mucoadhesive materials and mucus surface, such as electrostatic attraction, hydrogen bonding, van der Waals forces and mechanical interpenetration and entanglement. Of the in vitro test, commercial mucin is frequently used as a substitute for fresh mucin because of its reproducible quality and easy availability, although it does not possess the same viscoelastic properties as freshly isolated mucus gel (Madsen et al., 1996). Nevertheless, it is still proved to be effective to provide preliminary information about the interaction with mucoadhesive materials (He et al., 1998; Rossi et al., 2000).

Wang et al. (2001) utilized two kinds of commonly used commercial mucins with different content of sialic acid (Sigma mucin type III from porcine stomach - 1\% sialic acid and mucin type I-S from porcine pancreas $-12 \%$ sialic acid) to evaluate their interaction with gelatin by measuring absorbance via spectrophotometer. They showed that the interaction between gelatin and mucin changed dramatically in varying environmental conditions. In purified water, gelatin (IEP $=9.0)$ is positively charged, and a strong interaction with mucin was observed as a result of the electrostatic attraction between them under this condition. However, aminated gelatin, with a higher positive charge density (higher amino group content) than gelatin, showed a lower interaction with mucin at a low mucin concentration. This could be due to higher solubility of aminated gelatin in water than the gelatin. Moreover, Wang et al. (2001) observed a strong interaction at a higher mucin concentration even 
when the aminated gelatin concentration was relatively very low. In contrast, gelatin $($ IEP $=5.0)$ did not show any interaction with mucin in purified water because it carried a net negative charge as mucin did under this condition. In the case of PBS, gelatin (IEP =9.0), as well as gelatin (IEP $=5.0)$, showed no interaction with mucin, although gelatin $(I E P=9.0)$ was expected to reveal an electrostatic attraction with mucin as in the case of purified water (Fig. 8) (Wang et al., 2001). The results for gelatin were ascribed to the unfavorable biopolymer conformation in the presence of high electrolyte concentration where the gelatin was dehydrated, thus shielding the free amino group content and reducing the available positive charge. Furthermore, due to the existent electrolyte, the ionization of sialic acid residues of mucin was greatly reduced, the electrostatic attraction between mucin and gelatins decreased, hence resulting in a weakened interaction for all kinds of gelatins (Wang et al., 2001). A strong interaction between pig gastric mucins and polymer solutions of gelatin and chitosan at $\mathrm{pH} 5.5$ was also described by Silletti et al. (2007). It is also to note that the ion content of the solvent can mask/inhibit the electrostatic interaction between positively charged gelatin and negatively charged mucin. For instance, when PBS buffer was used as solvent, positively charged gelatin showed no interaction with mucin, although positively charged gelatin was expected to reveal an electrostatic attraction with mucin as in the case of purified water. On the other hand, in our recent study (Celebioglou 2016) electrostatic interaction was observed between positively charged BLG and negatively charged mucin dissolved in PBS buffer. Low field NMR results suggested that indeed the interaction of proteins with hydrogen ions in water/solvent systems did not mask/block the BLGmucin interaction (Celebioglou, et al. 2015, 2016).

Mucin was identified by van Ruth et al. (1995) as the key component in saliva to affect flavour release, by binding to and reducing the release of hydrophobic compounds. Saliva/mucin has been shown to influence both the thermodynamic and kinetic components of flavour release from the gel systems by 
Boland et al. (2004). The largest effect was observed with the most rigid gel, the gelatin gel, where saliva caused large increases in flavour release, due to an increased surface area for diffusion of flavour compounds. Saliva has ability to enhance the water content of the system, thereby increasing the surface area available for the diffusion of flavour compounds. This effect was found for the gelatin gel since it was a rigid gel and the addition of saliva seems to level out the influence of the gel rigidity (Boland et al. 2004).

The reported interaction of mucin with many biologically important entities including biopolymers prompted the preparation of microspheres from admixtures of mucin and gelatin (a widely used pharmaceutical adjuvant). Ofokansi et al. (2007), therefore, aimed to prepare microspheres from admixtures of gelatin and mucin and to evaluate the in vitro and in vivo delivery of ceftriaxone sodium from these microspheres. They observed that microspheres prepared from admixtures of gelatin and S-mucin adsorbed greater amounts of ceftriaxone $(\mathrm{p}=0.05)$ in comparison with those prepared from gelatin alone. Thus, they have concluded that in the presence of mucin, the intermolecular network and possibly other characteristics of gelatin were modified. The water sorption behavior in the two media further confirmed a modification of the gelatin microspheres by the mucin (Ofokansi et al., 2007). A possible enhancement of the mucoadhesive properties of gelatin microspheres by the soluble portion of porcine mucin due to the modified intermolecular network and possibly other characteristics of gelatin in the presence of mucin was suggested in another study by Ofokansi et al. (2009).

\subsection{Mucin interaction with galectin/lectin (carbohydrate binding proteins) /proline-rich-} proteins 
Although mucin plays a key role in the function and properties of mucus, it is the synergistic interaction of mucin with smaller proteins, salts, immunoglobulins, and water, which gives mucus its characteristic slimy, viscoelastic property that is responsible for the exceptional lubricating ability of saliva (Feilier et al., 2007). A number of studies have shown that the rheological properties of mucins vary enormously depending on the type (membrane or secreted) and source (human or animal) and the level of purification, and inclusion of other proteins as well as solution conditions (Bansil et al. 1995; Pearson et al., 200; Taylor et al., 2005).

An understanding of the biochemistry behind the known interactions between mucins and other proteins, coupled with an appreciation of their pathophysiological significance, can lend insight into the development of novel therapeutic agents. For instance, cancer-associated alteration in the peripheral carbohydrates of colonic mucins can serve as ligands for galactoside-binding protein galectin-3, which is expressed at higher levels in colon cancer than normal colon, binds to colon cancer mucin. Therefore, binding of galectin-3 to mucin may show therapeutic or preventative promise for colon cancer (Byrd et al. 2004). The binding of galectin-3 is carbohydrate-dependent but is also influenced by the N-terminal domain, since phosphorylation of serine residue 6 reversibly inhibits binding of galectin-3 to colon cancer mucin (Cooper, 2002).

Wirth et al. (2002) investigated both binding rate and specificity of the mucus-lectin interaction; the binding of fluorescent-labelled analogues of plant lectins with different carbohydrate specificity to the pig gastric mucin coated microplates was studied. Even though the viscoelastic properties of the gastrointestinal mucus were not mimicked by this assay, the qualitative composition of pig gastric mucin reflects that of the human one. At neutral $\mathrm{pH}$, the lectin-binding capacity of mucin followed the order wheat germ agglutinin (WGA) (sialic acid and N-acetyl-Dglucosamine) $>>$ Ulex europaeus isoagglutinin I (alpha- L-fucose) $>>$ lentil lectin (alpha mannose) = potato lectin (N-acetyl-Dglucosamine) $>$ peanut lectin (galactosamine) $>$ Dolichos biflorus agglutinin (N-acetyl- 
galactosamine). This ranking rather reflects the steric accessibility of the mucus proteins than the molar composition of mucins. As sialic acids often operate as chain terminators at the linear or branched glycoproteins, the WGA-binding was highest. The mucin-lectin interaction is characterised by pH-dependence, specificity, and reversibility (Wirth et al., 2002). The highest WGA binding rates were observed at $\mathrm{pH} 5$. At $\mathrm{pH} 2$, the PGM-bound WGA decreased by about $15 \%$ compared to $\mathrm{pH} 5.0$ values and at $\mathrm{pH}$ 6.0-7.0, PGM-binding of the lectin was in the range of $60-70 \%$ compared to $\mathrm{pH} 5.0$ values. Overall, it is expected that the strong and specific interaction between mucin and lectindecorated formulations will result in anchoring of the drug delivery system at the site of absorption (Gabor et al., 2004).

Moreover, Dam et al. (2007) indicated that the longer polypeptide chain forms of porcine submaxillary gland mucins bind with higher affinities to the lectins, and that the total numbers of free GalNAc residues in porcine submaxillary gland mucins are important for binding to the lectins. They also proposed the internal diffusion model of a lectin jumping from carbohydrate epitope to epitope in a mucin chain is similar to that for a variety of ligands binding to DNA in which binding and sliding occur along the DNA backbone (von Hippel, 2007; Dam et al., 2007).

Argueso et al. (2009) investigated a new role for the carbohydrate-binding protein galectin-3 in stabilizing mucosal barriers through its interaction with mucins on the apical glycocalyx. Using the surface of the eye as a model system, they found that galectin-3 colocalized with two distinct membrane-associated mucins, MUC1 and MUC16, on the apical surface of epithelial cells and that both mucins bound to galectin-3 affinity columns in a galactose dependent manner. These results suggest that galectin-3 plays a key role in maintaining mucosal barrier function through carbohydratedependent interactions with cell surface mucins. Regarding the mechanism by which the mucingalectin-3 interaction contributes to the integrity of the mucosal barrier, they proposed that mucins, which are defined by the presence of amino acid tandem repeat domains with multiple $O$-glycan 
chains, form strong complexes with multivalent galectin-3 at the epithelial cell surface, as shown in the model in Figure. 9.

Furthermore, Zhao et al. (2010) have shown that the transmembrane mucin protein MUC1 is an endogenous ligand of galectin-3 in human colon cancer cells and that the interaction between MUC1 and galectin-3 occurs via binding of galectin-3 to the oncofetal Thomsen-Friedenreich carbohydrate (Gal $\beta 1,3$ GalNAc $\alpha-$, T or TF) antigen on MUC1. They mentioned that the galectin-3-MUC1 interaction induces MUC1 cell surface polarization and exposure of the cell surface adhesion molecules (Fig. 10).

Overall, it is shown that carbohydrate structures present in the highly glycosylated region of mucins make them potential candidates to interact with the galectin family of carbohydrate binding proteins (b-galactoside-specific lectins). In addition, immunological evidence demonstrates that MUC5B interacts with histatin and proline-rich proteins (PRPs) in human salivary fluid (Iontcheva et al., 1997). The MUC5B-histatin interaction is a direct protein-protein interaction mediated by the MUC5B Cys1, Cys2, and Cys8a (Iontcheva et al., 2000). By contrast, the interaction sites for PRPs remain uncharacterized. Another secretory mucin, MUC7 also interacts directly with PRP2, an acidic PRP via its N-terminal region (Bruno et al. 2005). In order to identify additional MUC7 interacting proteins, Soares et al., (2003) demonstrated that lactoferrin, an iron-binding protein, interacts directly with MUC7 in a glycosylation-independent manner. In human saliva, alpha-amylase (a glycoside hydrolase) also interacts with MUC5B and MUC7 (Iontcheva et al., 1997; Bruno et al., 2005). The $\mathrm{N}$-terminal region of MUC7 participates in the direct interaction between these two proteins. However, the nature of the $\alpha$-amylase-MUC5B interaction, which was suggested to be non-covalent, remains incompletely characterized. Like histatins, statherin, another salivary protein, interacts directly with MUC5B; the MUC5B Cys8a-subdomain forms the binding site for statherin. The involvement of the MUC5B Cys1-, Cys2- and Cys8a-subdomains in directing interactions with 
statherin and histatins suggests that these proteins undergo a glycosylation-independent interaction (Senapati et al., 2010). However, further studies are needed to clarify the involvement of glycosylation or phosphorylation in the binding events of histatins and statherin with MUC5B Cys1, Cys2- and Cys8a-subdomains since these regions are predicted to have a low number of potential glycosylation sites in their primary structure (Iontcheva et al., (2000). Interactions between secretory mucins and the aforementioned other salivary proteins seem to be very important in the maintenance of oral physiology (Senapati et al., 2010). Experimental evidence indicates that PRP and statherin promote salivary calcium homeostasis. Statherins are also believed to promote the binding of helpful bacteria to the enamel surface. By contrast, the antimicrobial activities of histatins and lactoferins represent a major component of the non-immune host-defense system in the human oral cavity. Therefore, interactions between salivary mucins and various other salivary proteins might help to enhance their stability and function.

\section{Concluding remarks}

Despite the fact that the physiology of the oral cavity is well studied, little is known about the oral behavior of food proteins and food-protein-stabilized emulsions. Thus, in the last decade there is a growing interest on mucin-protein interaction relating to the food oral processing and digestion. The interactions of salivary mucins and saliva with several food proteins and food protein emulsions, as well as their functional properties related to the food oral processing, were reviewed in this paper. The food proteins of focus were whey proteins (lactoferrin and beta-lactoglobulin) and non-whey proteins (casein, gelatin, galectin/lectin, and proline-rich proteins).

A number of experimental methods have been developed and utilized to study mucin/saliva interactions with food proteins. For instance, sensory analysis with trained panelist, taste sensors, and 
viscoelastic measurements were used to observe changes in the taste perception after mucin/saliva interaction with food proteins due to the protein aggregation. Tribology tests were developed to measure friction by mimicking the rubbing contacts in oral cavity lubricated by mucin/saliva and/or food protein solution/emulsion. Moreover, several spectroscopies were used to understand in detail the molecular level interaction and the structural changes of proteins. On the other hand, especially for drug delivery purposes, mucoadhesion properties of protein-mucin system via turbimetric measurements and surface adsorption techniques were commonly used.

Most of the studies suggest that electrostatic attraction is the main mode for the interaction between positively charged proteins with negatively charged moieties of mucin (mainly on glycosylated region of mucin). However, our recent studies related to the BLG-mucin interactions were the first to clearly suggest the importance of hydrophobic as well as the hydrophilic interactions such as hydrogen bonding. Several important subjects, such as hydrophobic surface adsorption, structural and functional changes due to hydrophobic attraction in addition to the hydrophilic ones, were proposed. In addition, the lubrication properties of BLG-saliva systems were determined in terms of strong aggregation between them.

Furthermore, studies of model saliva (with and without mucin) on the stability of protein emulsions as well as on the effects of food proteins on the adsorption and/or lubrication properties of saliva, suggested the significant differences on the emulsion stability, and/or on the lubrication properties of saliva that were observed when mucin was present in the food-saliva model. This indicates the importance of mucin (rather than saliva) to the mucin/saliva interactions with food proteins. Moreover, the sign and the density of the charge on the surface of the protein emulsion droplets contribute significantly to the behavior of the emulsion when mixed with saliva. Depending on the protein charge, saliva-induced emulsion flocculation is driven by two different main mechanisms, namely, depletion flocculation and electrostatic attraction. 
Overall, further studies are required to address in detail the hydrophobic and hydrophilic interactions attraction between mucin and (food) proteins. Moreover, despite the similar interaction mechanisms of mucin with other proteins and peptides, the conformation of the mucin and the other proteins, after the interaction take place, mostly determine their functional properties. 


\section{References}

Argüeso, P., Guzman-Aranguez, A., Mantelli, F., Cao, Z., Ricciuto, J., and Panjwani, N. (2009). Association of cell surface mucins with galectin-3 contributes to the ocular surface epithelial barrier. Journal of Biological Chemistry. 284(34): 23037-23045.

Bansil, R., and Turner, B. S. (2006). Mucin structure, aggregation, physiological functions and biomedical applications. Current Opinion in Colloid \& Interface Science. 11(2-3): 164-170.

Bansil, R., Stanley, E., and LaMont, J. T. (1995). Mucin biophysics. Annual Review of Physiology. 57: 635-657.

Barylko-Pikielna, N., Martin, A., and Mela, D. J. (1994). Perception of taste and viscosity of oil-inwater and water-in-oil emulsions. Journal of Food Science. 59(6): 1318-1321.

Beecher, J. W., Drake, M. A., Luck, P. J., and Foegeding, E. A. (2008). Factors regulating astringency of whey protein beverages. Journal of dairy science. 91(7): 2553-2560.

Blijdenstein, T. B. J., Hendriks, W. P. G., van der Linden, E., van Vliet, T., and van Aken, G. A. (2003). Control of strength and stability of emulsion gels by a combination of long- and shortrange interactions. Langmuir. 19(17): 6657-6663.

Blijdenstein, T. B. J., van Vliet, T., van der Linden, E., and van Aken, G. A. (2003). Suppression of depletion flocculation in oil in water emulsions: a kinetic effect of beta-lactoglobulin. Food Hydrocolloids. 17(5): 661-669. 
Boland, A. B., Buhr, K., Giannouli, P., and Van Ruth, S. M. (2004). Influence of gelatin, starch, pectin and artificial saliva on the release of 11 flavour compounds from model gel systems. Food Chemistry. 86(3): 401-411.

Brownlow, S., Cabral, J. H. M., Cooper, R., Flower, D. R., Yewdall, S. J., Polikarpov, I., ... and Sawyer, L. (1997). Bovine $\beta$-lactoglobulin at $1.8 \AA$ resolution—still an enigmatic lipocalin. Structure. 5(4): 481-495.

Bruno, L. S., Li, X., Wang, L., Soares, R. V., Siqueira, C. C., Oppenheim, F. G., ... and Offner, G. D. (2005). Two-hybrid analysis of human salivary mucin MUC7 interactions. Biochimica et Biophysica Acta (BBA)-Molecular Cell Research. 1746(1): 65-72.

Byrd, J. C., and Bresalier, R. S. (2004). Mucins and mucin binding proteins in colorectal cancer. Cancer and Metastasis Reviews. 23(1-2): 77-99.

Çelebioğlu, H. Y., Gudjónsdóttir, M., Chronakis, I. S., and Lee, S. (2016). Investigation of the interaction between mucins and $\beta$-lactoglobulin under tribological stress. Food Hydrocolloids. 54: $57-65$.

Çelebioğlu, H. Y., Gudjónsdóttir, M., Meier, S., Duus, J. Ø., Lee, S., and Chronakis, I. S. (2015). Spectroscopic studies of the interactions between $\beta$-lactoglobulin and bovine submaxillary mucin. Food Hydrocolloids. 50: 203-210.

Çelebioğlu, H. Y., Kmiecik, J., Lee, S., and Chronakis, I. S. (2017). Interfacial shear rheology of $\beta$ lactoglobulin - bovine submaxillary mucin layers adsorbed at air/water interface. International Journal of Biological Macromolecules. 102: 857-867. 
Chen, J., and Stokes, J. R. (2012). Rheology and tribology: Two distinctive regimes of food texture sensation. Trends in Food Science \& Technology. 25(1): 4-12.

Chen, J., Liu, Z., and Prakash, S. (2014). Lubrication studies of fluid food using a simple experimental set up. Food Hydrocolloids. 42: 100-105.

Chojnicka-Paszun, A., de Jongh, H. H. J., and de Kruif, C. G. (2012). Sensory perception and lubrication properties of milk: Influence of fat content. International Dairy Journal. 26: 15-22.

Condelli, N., Dinnella, C., Cerone, A., Monteleone, E., and Bertuccioli, M. (2006). Prediction of perceived astringency induced by phenolic compounds II: Criteria for panel selection and preliminary application on wine samples. Food Quality and Preference. 17(1): 96-107.

Cooper, D. N. (2002). Galectinomics: finding themes in complexity. Biochimica et Biophysica Acta (BBA)-General Subjects. 1572(2): 209-231.

Dam, T. K., Gerken, T. A., Cavada, B. S., Nascimento, K. S., Moura, T. R., and Brewer, C. F. (2007). Binding studies of $\alpha$-GalNAc-specific lectins to the $\alpha$-GalNAc (Tn-antigen) form of porcine submaxillary mucin and its smaller fragments. Journal of Biological Chemistry. 282(38): 28256-28263.

de Roos, K. B. (2003). Effect of texture and microstructure on flavour retention and release. International Dairy Journal. 13(8): 593-605.

de Wijk, R. A., van Gemert, L. J., Terpstra, M. E. J., and Wilkinson, C. L. S. O. (2003). Texture of semi-solids; sensory and instrumental measurements on vanilla custard desserts. Food Quality and Preference. 14(4): 305-317. 
Dekker, J., Rossen, J. W., Büller, H. A., and Einerhand, A. W. (2002). The MUC family: an obituary. Trends in biochemical sciences. 27(3): 126-131.

Di Silvio, D., Rigby, N., Bajka, B., Mayes, A., Mackie, A., and Bombelli, F. B. (2015). Technical tip: high-resolution isolation of nanoparticle-protein corona complexes from physiological fluids. Nanoscale. 7(28): 11980-11990.

Dickinson, E. (2003). Hydrocolloids at interfaces and the influence on the properties of dispersed systems. Food Hydrocolloids. 17(1): 25-39.

Dickinson, E., and Pawlowsky, K. (1997). Influence of iota-carrageenan on flocculation, creaming and rheology of a protein-stabilized emulsion. Journal of Agriculture and Food Chemistry. 45: $3799-3806$.

Doyen, K., Carey, M., Linforth, R. S. T., Marin, M., and Taylor, A. J. (2001). Volatile release from an emulsion: headspace and in-mouth studies. Journal of Agriculture and Food Chemistry. 49(2): 804-810.

Durrer, C., Irache, J. M., Duchene, D., and Ponchel, G. (1995). Mucin Interactions with Functionalized Polystyrene Latexes. Journal of Colloid and Interface Science. 170(2): 555-561.

Edwards, P. B., Creamer, L. K., and Jameson, G. B. (2009). Structure and stability of whey proteins. In: Milk proteins: From expression to food, pp. 163-203. Thompson, A., Boland, M., and Singh, H.. Eds., Academic Press, New York.

Efremova, N. V., Huang, Y., Peppas, N. A., and Leckband, D. E. (2002). Direct Measurement of Interactions between Tethered Poly ( ethylene glycol ) Chains and Adsorbed Mucin Layers. Langmuir. 18(3): 836-845. 
Engelen, L., de Wijk, R. A., Prinz, J. F., and Bosman, F. (2003). The relation between saliva flow after different stimulations and the perception of flavor and texture attributes in custard desserts. Physiology and Behavior. 78: 165-169.

Engelen, L., van den Keybus, P. A., de Wijk, R. A., Veerman, E. C., Amerongen, A. V. N., Bosman, F., ... and van der Bilt, A. (2007). The effect of saliva composition on texture perception of semisolids. Archives of Oral Biology. 52(6): 518-525.

Fang, Y., and Dalgleish, D. (1997). Conformation of beta-Lactoglobulin Studied by FTIR: Effect of $\mathrm{pH}$, Temperature, and Adsorption to the Oil-Water Interface. Journal of Colloid and Interface Science. 196(2): 292-298.

Feiler, A. A., Sahlholm, A., Sandberg, T., and Caldwell, K. D. (2007). Adsorption and viscoelastic properties of fractionated mucin (BSM) and bovine serum albumin (BSA) studied with quartz crystal microbalance (QCM-D). Journal of colloid and interface science. 315(2): 475-481.

Gabor, F., Bogner, E., Weissenboeck, A., and Wirth, M. (2004). The lectin-cell interaction and its implications to intestinal lectin-mediated drug delivery. Advanced drug delivery reviews. 56(4): 459-480.

Guo, T., Rudnick, P. A., Wang, W., Lee, C. S., DeVoe, D. L., and Balgley, B. M. (2006). Characterization of the human salivary proteome by capillary isoelectric focusing/nanoreversedphase liquid chromatography coupled with ESI-tandem MS. Journal of proteome research. 5(6): $1469-1478$.

Guzey, D., and McClements, D. J. (2006). Formation, stability and properties of multilayer emulsions for application in the food industry. Advances in Colloid and Interface Science. 128: 227-248. 
Hagerman, A. E., and Butler, L. G. (1980). Determination of protein in tannin-protein precipitates. Journal of Agricultural Food Chemistry. 28: 944-947.

Haslam, E. (1974). Polyphenol-protein interactions. Biochemical Journal. 139: 285-288.

He, P., Davis, S.S., and Illum, L. (1998). In vitro evaluation of the mucoadhesive properties of chitosan microspheres. International Journal of Pharmaceutics. 166: 75-88.

Healy, T. W., and Lamer, V. K. (1964). Energetics of flocculation and redispersion by polymers. Journal of Colloid Science. 19(4): 323-332.

Holt, C., Carver, J. A., Ecroyd, H., and Thorn, D. C. (2013). Invited review: Caseins and the casein micelle: their biological functions, structures, and behavior in foods. Journal of Dairy Science. 96(10): 6127-6146.

Hägerström, H., and Edsman, K. (2003). Limitations of the rheological mucoadhesion method: the effect of the choice of conditions and the rheological synergism parameter. European Journal of Pharmaceutical Sciences. 18(5): 349-357.

Iontcheva, I., Oppenheim, F. G., and Troxler, R. F. (1997). Human salivary mucin MG1 selectively forms heterotypic complexes with amylase, proline-rich proteins, statherin, and histatins. Journal of Dental Research. 76(3): 734-743.

Iontcheva, I., Oppenheim, F. G., Offner, G. D., and Troxler, R. F. (2000). Molecular mapping of statherin-and histatin-binding domains in human salivary mucin MG1 (MUC5B) by the yeast two-hybrid system. Journal of Dental Research. 79(2): 732-739. 
Jobstyl, E., O’Connell, J., Fairclough, J. P. A., and Williamson, M. P. (2004). Molecular model for astringency produced by polyphenol/protein interactions. Biomacromolecules. 5(3): 942-949.

Johnston-Banks, F. A. (1990). Gelatine. In: Food gels, pp. 233-289. Harris, P., Eds., Elsevier Science, London.

Joyner Melito, H. S., Pernell, C. W., and Daubert, C. R. (2014). Impact of formulation and saliva on acid milk gel friction behavior. Journal of Food Science. 79: 67-80.

Kawasaki, K., and Weiss, K. M. (2003). Mineralized tissue and vertebrate evolution: the secretory calcium-binding phosphoprotein gene cluster. Proceedings of the National Academy of Sciences. 100(7): 4060-4065.

Kawasaki, K., Lafont, A. G., and Sire, J. Y. (2011). The evolution of milk casein genes from tooth genes before the origin of mammals. Molecular Biology and Evolution. 28(7): 2053-2061.

Kawasaki, K., Suzuki, T., and Weiss, K. M. (2004). Genetic basis for the evolution of vertebrate mineralized tissue. Proceedings of the National Academy of Sciences of the United States of America. 101(31): 11356-11361.

Kelly, M., Vardhanabhuti, B., Luck, P., Drake, M. A., Osborne, J., and Foegeding, E. A. (2010). Role of protein concentration and protein-saliva interactions in the astringency of whey proteins at low pH. Journal of Dairy Science. 93(5): 1900-1909.

Kilcast, D., and Clegg, S. (2002). Sensory perception of creaminess and its relationship with food structure. Food Quality and Preference. 13: 609-623. 
Kinsella, J. E., and Whitehead, D. M. (1989). Proteins in whey: chemical, physical, and functional properties. Advances in Food and Nutrition Research. 33: 343-438.

Kontopidis, G., Holt, C., and Sawyer, L. (2004). Invited review: beta-lactoglobulin: binding properties, structure, and function. Journal of Dairy Science. 87(4): 785-96.

Kosters, H. A., Wierenga, P. A., de Vries, R., and Gruppen, H. (2013). Protein-peptide interaction: study of heat-induced aggregation and gelation of $\beta$-lactoglobulin in the presence of two peptides from its own hydrolysate. Journal of Agricultural and Food Chemistry. 61: 4218-4225.

Kralova, I., and Sjoblom, J. (2009). Surfactants used in food industry: a review. Journal of Dispersion Science and Technology. 30(9): 1363-1383.

Lai, S. K., Wang, Y. Y., and Hanes, J. (2009). Mucus-penetrating nanoparticles for drug and gene delivery to mucosal tissues. Advanced Drug Delivery Reviews. 61(2): 158-171.

Lee, S., Müller, M., Rezwan, K., and Spencer, N. D. (2005). Porcine gastric mucin (PGM) at the water/poly(dimethylsiloxane) (PDMS) interface: influence of $\mathrm{pH}$ and ionic strength on its conformation, adsorption, and aqueous lubrication properties. Langmuir : The ACS Journal of Surfaces and Colloids. 21: 8344-8353.

Lehr, C. M. (1994). Bioadhesion technologies for the delivery of peptide and protein drugs to the gastrointestinal tract. Critical Reviews in Therapeutic Drug Carrier Systems. 11(2): 119-160.

Lemay, D. G., Lynn, D. J., Martin, W. F., Neville, M. C., Casey, T. M., Rincon, G., ... and Pollard, K. S. (2009). The bovine lactation genome: insights into the evolution of mammalian milk. Genome Biology. 10(4): 43. 
Livney, Y. D. (2010). Milk proteins as vehicles for bioactives. Current Opinion in Colloid \& Interface Science. 15(1-2): 73-83.

Madsen, F., Eberth, K., and Smart, J.D. (1996). A rheological evaluation of various mucus gels for use in in vitro mucoadhesion testing. Pharmaceutical Science. 2: 563-566.

Madsen, J. B., Sotres, J., Pakkanen, K. I., Efler, P., Svensson, B., Abou Hachem, M., ... and Lee, S. (2016). Structural and Mechanical Properties of Thin Films of Bovine Submaxillary Mucin versus Porcine Gastric Mucin on a Hydrophobic Surface in Aqueous Solutions. Langmuir. 32(38): 9687-9696.

Majhi, P. R., Ganta, R. R., Vanam, R. P., Seyrek, E., Giger, K., and Dubin, P. L. (2006). Electrostatically Driven Protein Aggregation: $\beta$-Lactoglobulin at Low Ionic Strength. Langmuir. 22(22): 9150-9159.

Malone, M. E., Appelqvist, I. A. M., and Norton, I. T. (2003). Oral behaviour of food hydrocolloids and emulsions. Part 1. Lubrication and deposition considerations. Food Hydrocolloids. 17(6): $763-773$.

Mandalari, G., Mackie, A. M., Rigby, N. M., Wickham, M. S., \& Mills, E. N. (2009). Physiological phosphatidylcholine protects bovine beta-lactoglobulin from simulated gastrointestinal proteolysis. Molecular Nutrition \& Food Research. 53(1): 131-139.

McClements, D. J. (2004). Protein-stabilized emulsions. Current Opinion in Colloid \& Interface Science. 9(5): 305-313. 
Mehrotra, R., Thornton, D., and Sheehan, J. (1998). Isolation and physical characterization of the MUC7 (MG2) mucin from saliva: evidence for self-association. Biochemical Journal. 334: 415422.

Mei, L. Y., McClements, D. J., and Decker, E. A. (1999). Lipid oxidation in emulsions as affected by charge status of antioxidants and emulsion droplets. Journal of Agricultural and Food Chemistry. 47(6): 2267-2273.

Mei, L. Y., McClements, D. J., Wu, J. N., and Decker, E. A. (1998). Iron-catalyzed lipid oxidation in emulsion as affected by surfactant, $\mathrm{pH}$ and $\mathrm{NaCl}$. Food Chemistry. 61(3): 307-312.

Menchicchi, B., Fuenzalida, J. P., Bobbili, K. B., Hensel, A., Swamy, M. J., and Goycoolea, F. M. (2014). Structure of chitosan determines its interactions with mucin. Biomacromolecules. 15: $3550-3558$.

Menchicchi, B., Fuenzalida, J. P., Hensel, A., Swamy, M. J., David, L., Rochas, C., and Goycoolea, F. M. (2015). Biophysical analysis of the molecular interactions between polysaccharides and mucin. Biomacromolecules. 16: 924-935.

Metcalf, K. L., and Vickers, Z. M. (2002). Taste intensities of oil-in-water emulsions with varying fat content. Journal of Sensory Studies. 17: 379-390.

Methven, L., Rahelu, K., Economou, N., Kinneavy, L., Ladbrooke-Davis, L., Kennedy, O. B., ... and Gosney, M. A. (2010). The effect of consumption volume on profile and liking of oral nutritional supplements of varied sweetness: Sequential profiling and boredom tests. Food Quality and Preference. 21(8): 948-955. 
Meyer, D., Vermulst, J., Tromp, R. H., and de Hoog, E. H. A. (2011). The Effect of inulin on tribology and sensory profiles of skimmed milk. Journal of Texture Studies. 42: 387-393.

Miettinen, S.-M., Tuorila, H., Piironen, V., Vehkalahti, K., and Hyvonen, L. (2002). Effect of emulsion characteristics on the release of aroma as detected by sensory evaluation, static headspace gas chromatography, and electronic nose. Journal of Agriculture and Food Chemistry. 50(15): 4232-4239.

Monteleone, E., Condelli, N., Dinnella, C., and Bertuccioli, M. (2004). Prediction of perceived astringency induced by phenolic compounds. Food Quality and Preference. 15(7): 761-769.

Moreno, F. J., Mackie, A. R., and Mills, E. N. C. (2005). Phospholipid interactions protect the milk allergen alpha-lactalbumin from proteolysis during in vitro digestion. Journal of Agricultural and Food Chemistry. 53(25): 9810-9816.

Nikogeorgos, N., Madsen, J. B., and Lee, S. (2014). Influence of impurities and contact scale on the lubricating properties of bovine submaxillary mucin (BSM) films on a hydrophobic surface. Colloids and Surfaces B: Biointerfaces. 122: 760-766.

Nordman, H., Davies, J. R., Lindell, G., de Bolos, C., Real, F., and Carlsted, I. (2002). Gastric MUC5AC and MUC6 are large oligomeric mucins that differ in size, glycosylation and tissue distribution. Biochemical Journal. 364: 191-200.

Ofokansi, K. C., Okore, V. C., and Adikwu, M. U. (2009). Biodegradable Microspheres Based on Gelatin-Porcine Mucin Admixtures: in Vitro and in Vivo Delivery Studies. Biological and Pharmaceutical Bulletin. 32(10): 1754-1759. 
Ofokansi, K. C., Adikwu, M. U., and Okore, V. C. (2007). Preparation and evaluation of mucingelatin mucoadhesive microspheres for rectal delivery of ceftriaxone sodium. Drug Development and Industrial Pharmacy. 33(6): 691-700.

Pascal, C., Poncet-Legrand, C., Cabane, B., and Vernhet, A. (2008). Aggregation of a proline-rich protein induced by epigallocatechin gallate and condensed tannins: Effect of protein glycosylation. Journal of Agricultural and Food Chemistry. 56(15): 6724-6732.

Pearson, J. P., Allen, A., and Hutton, D. A. (2000). Rheology of mucin. Glycoprotein Methods and Protocols: The Mucins. 99-109.

Peppas, N. A., and Robinson, J. R. (1995). Bioadhesives for optimization of drug delivery. Journal of Drug Targeting. 3(3): 183-184.

Prakash, S., Tan, D. D. Y., and Chen, J. (2013). Applications of tribology in studying food oral processing and texture perception. Food Research International. 54: 1627-1635.

Qaqish, R., and Amiji, M. (1999). Synthesis of a fluorescent chitosan derivative and its application for the study of chitosan-mucin interactions. Carbohydrate Polymers. 38(2): 99-107.

Raikos, V. (2010). Effect of heat treatment on milk protein functionality at emulsion interfaces. A review. Food Hydrocolloids. 24(4): 259-265.

Rijnkels, M., Elnitski, L., Miller, W., and Rosen, J. M. (2003). Multispecies comparative analysis of a mammalian-specific genomic domain encoding secretory proteins. Genomics. 82(4): 417-432. 
Rossi, S., Ferrari, F., Bonferoni, M.C., and Caramella, C. (2000). Characterization of chitosan hydrochloride-mucin interaction by means of viscosimetric and turbidimetric measurements. European Journal of Pharmaceutical Science. 10: 251-257.

Sakurai, K., and Goto, Y. (2002). Manipulating monomer-dimer equilibrium of bovine $\beta$ lactoglobulin by amino acid substitution. Journal of Biological Chemistry. 277(28): 2573525740.

Sakurai, K., Konuma, T., Yagi, M., and Goto, Y. (2009). Structural dynamics and folding of $\beta$ lactoglobulin probed by heteronuclear NMR. Biochimica et Biophysica Acta (BBA)-General Subjects. 1790(6): 527-537.

Sakurai, K., Oobatake, M., and Goto, Y. (2001). Salt-dependent monomer-dimer equilibrium of bovine $\beta$-lactoglobulin at $\mathrm{pH}$ 3. Protein Science. 10(11): 2325-2335.

Sandberg, T., Blom, H., and Caldwell, K. D. (2009). Potential use of mucins as biomaterial coatings. I. Fractionation, characterization, and model adsorption of bovine, porcine, and human mucins. Journal of Biomed Materials Research A. 91: 762-772.

Sano, H., Egashira, T., Kinekawa, Y., and Kitabatake, N. (2005). Astringency of bovine milk whey protein. Journal of Dairy Science. 88(7): 2312-2317.

Sarkar, A., Goh, K. K. T., and Singh, H. (2010). Properties of oil-in-water emulsions stabilized by blactoglobulin in simulated gastric fluid as influenced by ionic strength and presence of mucin. Food Hydrocolloids. 24: 534-541.

Sarkar, A., Goh, K. K. T., Singh, R. P., and Singh, H. (2009). Behaviour of an oil-in-water emulsion stabilized by b-lactoglobulin in an in vitro gastric model. Food Hydrocolloids. 23: 1563-1569. 
Selway, N., and Stokes, J. R. (2013). Insights into the dynamics of oral lubrication and mouth feel using soft tribology: Differentiating semi-fluid foods with similar rheology. Food Research International. 54: 423-431.

Senapati, S., Das, S., and Batra, S. K. (2010). Mucin-interacting proteins: from function to therapeutics. Trends in Biochemical Sciences. 35(4): 236-45.

Shi, L., Ardehali, R., Caldwell, K. D., and Valint, P. (2000). Mucin coating on polymeric material surfaces to suppress bacterial adhesion. Colloids and Surfaces B: Biointerfaces. 17: 229-239.

Shrivastava, H. Y., and Nair, B. U. (2003). Structural modification and aggregation of mucin by chromium(III) complexes. Journal of Biomolecular Structure \& Dynamics. 20(4): 575-87.

Silletti, E., Vingerhoeds, M. H., Norde, W., and Van Aken, G. A. (2007). The role of electrostatics in saliva-induced emulsion flocculation. Food Hydrocolloids. 21(4): 596-606.

Silletti, E., Vingerhoeds, M. H., Norde, W., and van Aken, G. A. (2007). Saliva-induced emulsion flocculation: role of droplet charge. In: Food Colloids, pp. 463-472. Dickinson, E., and Leser, M. E., Eds., Royal Society of Chemistry, Cambridge.

Silletti, E., Vitorino, R. M., Schipper, R., Amado, F. M., and Vingerhoeds, M. H. (2010). Identification of salivary proteins at oil-water interfaces stabilized by lysozyme and $\beta$ lactoglobulin. Archives of Oral Biology. 55(4): 268-278.

Singh, H. (2011). Aspects of milk-protein-stabilised emulsions. Food Hydrocolloids. 25(8): 19381944. 
Singh, H., and Ye, A. (2013). Structural and biochemical factors affecting the digestion of proteinstabilized emulsions. Current Opinion in Colloid \& Interface Science. 18(4): 360-370.

Soares, R. V., Siqueira, C. C., Bruno, L. S., Oppenheim, F. G., Offner, G. D., and Troxler, R. F. (2003). MG2 and lactoferrin form a heterotypic complex in salivary secretions. Journal of Dental Research. 82(6): 471-475.

Sotres, J., and Arnebrant, T. (2013). Experimental Investigations of biological lubrication at the nanoscale: the cases of synovial joints and the oral cavity. Lubricants. 1(4): 102-131.

Steijns, J. M., and van Hooijdonk, A. C. M. (2000). Occurrence, structure, biochemical properties and technological characteristics of lactoferrin. British Journal of Nutrition. 84: 11-17

Taulier, N., and Chalikian, T. V. (2001). Characterization of pH-induced transitions of betalactoglobulin: ultrasonic, densimetric, and spectroscopic studies. Journal of Molecular Biology. 314(4): 873-89.

Taylor, C., Pearson, J. P., Draget, K. I., Dettmar, P. W., and Smidsrød, O. (2005). Rheological characterisation of mixed gels of mucin and alginate. Carbohydrate Polymers. 59(2): 189-195.

Teng, Z., Luo, Y., Li, Y., and Wang, Q. (2016). Cationic beta-lactoglobulin nanoparticles as a bioavailability enhancer: effect of surface properties and size on the transport and delivery in vitro. Food Chemistry. 204: 391-399.

Tokle, T., Lesmes, U., and McClements, D. J. (2010). Impact of electrostatic deposition of anionic polysaccharides on the stability of oil droplets coated by lactoferrin. Journal of Agricultural and Food Chemistry. 58(17): 9825-9832. 
Uhrínová, S., Uhrín, D., Denton, H., Smith, M., Sawyer, L., and Barlow, P. N. (1998). Complete assignment of $1 \mathrm{H}, 13 \mathrm{C}$ and $15 \mathrm{~N}$ chemical shifts for bovine beta-lactoglobulin: secondary structure and topology of the native state is retained in a partially unfolded form. Journal of Biomolecular NMR. 12(1): 89-107.

van Aken, G. A. (2013). Acoustic emission measurement of rubbing and tapping contacts of skin and tongue surfaces in relation to tactile perception. Food Hydrocolloids. 31: 325-331.

van Aken, G. A., Vingerhoeds, M. H., and de Hoog, E. H. A. (2005). Colloidal behaviour of food emulsions under oral conditions. In: Food colloids, pp. 356-366. Dickinson, E., Eds., The Royal Society of Chemistry, Cambridge.

van Klinken, B. J. W., Einerhand, A. W. C., Buller, H. A., and Dekker, J. (1998). Strategic biochemical analysis of mucins. Analytical Biochemistry. 265: 103-116.

van Ruth, S. M., and Roozen, J. P. (2000a). Influence of mastication and saliva on aroma release in a model mouth system. Food Chemistry. 71: 339-345.

van Ruth, S. M., and Roozen, J. P. (2000b). Aroma compounds of oxidised sunflower oil and its oilin water emulsion: Volatility and release under mouth conditions. European Food Research and Technology. 210: 258-262.

van Ruth, S. M., Roozen, J. P., and Cozijnsen, J. L. (1995). Changes in flavour release from rehydrated diced bell peppers (Capsicumannuum) by artificial saliva components in three mouth model systems. Journal of the Science of Food and Agriculture. 67: 189-196. 
van Ruth, S., King, C., and Giannouli, P. (2002). Influence of lipid fraction, emulsifier fraction, and mean particle diameter of oil-in water emulsions on the release of 20 aroma compounds. Journal of Agriculture and Food Chemistry. 50: 2365-2371.

Vardhanabhuti, B., and Foegeding, E. A. (2010). Evidence of interactions between whey proteins and mucin: their implication on the astringency mechanism of whey proteins at low $\mathrm{pH}$. In: Gums and stabilisers for the food industry, pp. 137-146. Williams, P. A., and Phillips G. O., Eds., The Royal Society of Chemistry, Cambridge.

Vardhanabhuti, B., Cox, P. W., Norton, I. T., and Foegeding, E. A. (2011). Lubricating properties of human whole saliva as affected by $\beta$-lactoglobulin. Food Hydrocolloids. 25(6): 1499-1506.

Vardhanabhuti, B., Kelly, M. A., Luck, P. J., Drake, M. A., and Foegeding, E. A. (2010). Roles of charge interactions on astringency of whey proteins at low $\mathrm{pH}$. Journal of dairy science. 93(5): $1890-1899$.

Vingerhoeds, M. H., Blijdenstein, T. B., Zoet, F. D., and van Aken, G. A. (2005). Emulsion flocculation induced by saliva and mucin. Food Hydrocolloids. 19(5): 915-922.

von Hippel, P. H. (2007). From "simple" DNA-protein interactions to the macromolecular machines of gene expression. Annual Review of Biophysics and Biomolecular Structure. 36: 79-105.

Wang, J., Tabata, Y., Bi, D., and Morimoto, K. (2001). Evaluation of gastric mucoadhesive properties of aminated gelatin microspheres. Journal of Controlled Release. 73: 223-231.

Wang, J., Tauch, Y., Deguchi, Y., Morimoto, K., Tabata, Y., and Ikada, Y. (2000) Positively charged gelatin microspheres as gastric mucoadhesive drug delivery system for clearance of $\mathrm{H}$. pylori. Drug Delivery. 7: 237-243 
Wirth, M., Gerhardt, K., Wurm, C., and Gabor, F. (2002). Lectin-mediated drug delivery: influence of mucin on cytoadhesion of plant lectins in vitro. Journal of controlled release. 79(1): 183191.

Withers, C. A., Cook, M. T., Methven, L., Gosney, M. A., and Khutoryanskiy, V. V. (2013). Investigation of milk proteins binding to the oral mucosa. Food \& Function. 4(11): 1668-1674.

Withers, C. A., Lewis, M. J., Gosney, M. A., and Methven, L. (2014). Potential sources of mouth drying in beverages fortified with dairy proteins: A comparison of casein-and whey-rich ingredients. Journal of Dairy Science. 97(3): 1233-1247.

Yakubov, G. E., McColl, J., Bongaerts, J. H., and Ramsden, J. J. (2009). Viscous boundary lubrication of hydrophobic surfaces by mucin. Langmuir. 25: 2313-2321.

Yan, Y., Hu, J., and Yao, P. (2009). Effects of casein, ovalbumin, and dextran on the astringency of tea polyphenols determined by quartz crystal microbalance with dissipation. Langmuir. 25: 397402.

Ye, A., Streicher, C., and Singh, H. (2011). Interactions between whey proteins and salivary proteins as related to astringency of whey protein beverages at low $\mathrm{pH}$. Journal of Dairy Science. 94(12): $5842-5850$.

Ye, A., Zheng, T., Jack, Z. Y., and Singh, H. (2012). Potential role of the binding of whey proteins to human buccal cells on the perception of astringency in whey protein beverages. Physiology \& Behavior. 106(5): 645-650.

Zalewska, A., Zwierz, K., Zolkowski, K., and Gindzienski, A. (2000). Structure and biosynthesis of human salivary mucins. Acta Biochimica Polonica. 47(4): 1067-1079. 
Zhang, R., Zhang, Z., Zhang, H., Decker, E.A., and McClements, D. J. (2010). Influence of emulsifier type on gastrointestinal fate of oil-in-water emulsions containing anionic dietary fiber (pectin). Food Hydrocolloids. 45: 175-185.

Zhao, Q., Barclay, M., Hilkens, J., Guo, X., Barrow, H., Rhodes, J. M., and Yu, L. G. (2010). Interaction between circulating galectin-3 and cancer-associated MUC1 enhances tumour cell homotypic aggregation and prevents anoikis. Molecular Cancer. 9(1): 154.

Zúñiga, R. N., Tolkach, A., Kulozik, U., and Aguilera, J. M. (2010). Kinetics of formation and physicochemical characterization of thermally-induced beta-lactoglobulin aggregates. Journal of Food Science. 75(5): 261-268. 


\section{FIGURES}

Figure 1:

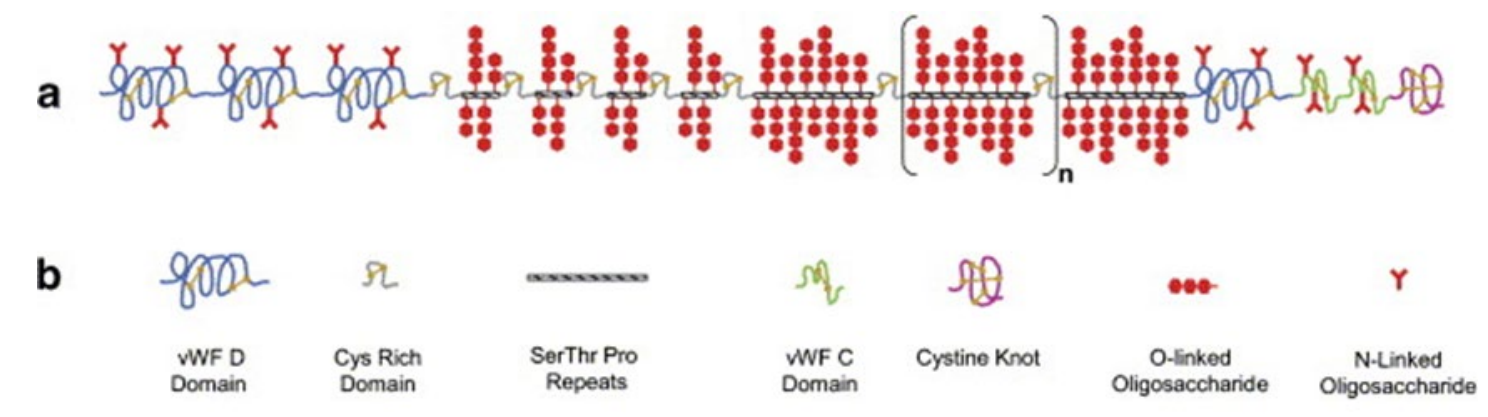

C

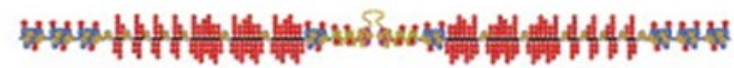

d

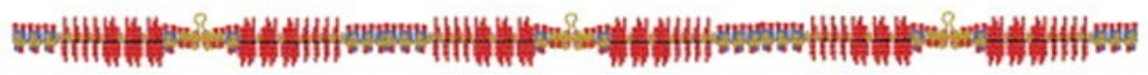

Fig.1. (a) A schematic drawing of the pig gastric mucin (PGM) monomer consisting of glycosylated regions flanked by regions with relatively little glycosylation. (b) The symbols indicate the different domains in the sketch in (a). (This representation is based in part on Figs. 1 and 2 of Dekker et al. (2002)). At the bottom of the figure showing (c) a dimer formed by two monomeric subunits linked via disulfide bonds in the non-glycosylated regions and in (d) dimers that are further disulfide linked to form higher multimers. This gives rise to the high molecular weight and polydispersity of secretory mucins. (Bansil and Turner, 2006). 
Figure 2:

A $\beta$-lg-st abilized emulsion-artificial saliva mixtures

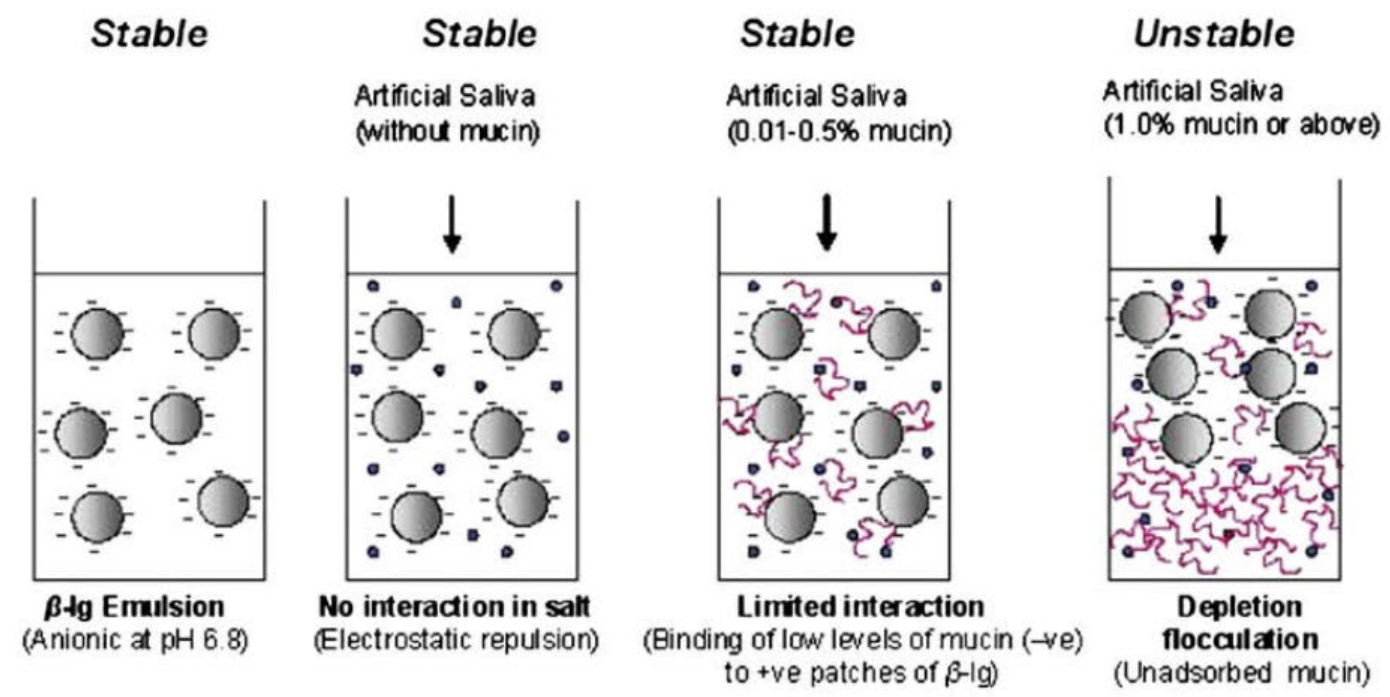

B

Lactof errin-stabilized emulsion-artificial saliva mixtures

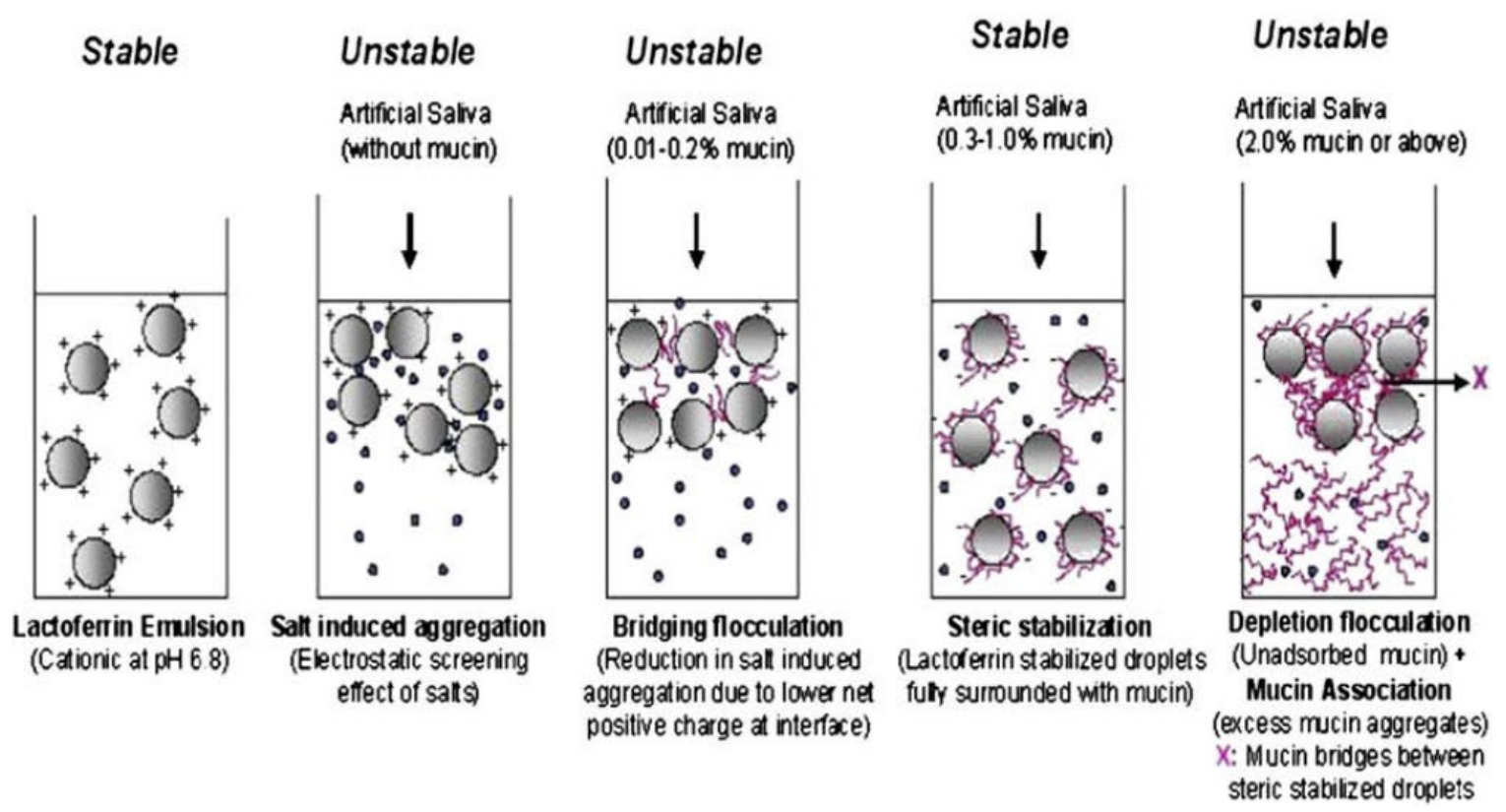

Fig. 2. Mechanisms of interaction in emulsion-saliva mixtures. Big shaded circle represents emulsion droplets; small solid dot represents salivary salts and coil structure represents mucin molecules. (a) BLG-stabilized emulsion interacting with artificial saliva (b) lactoferrin-stabilized emulsion interacting with artificial saliva. (Sarkar et al. 2009) 


\section{Figure 3:}

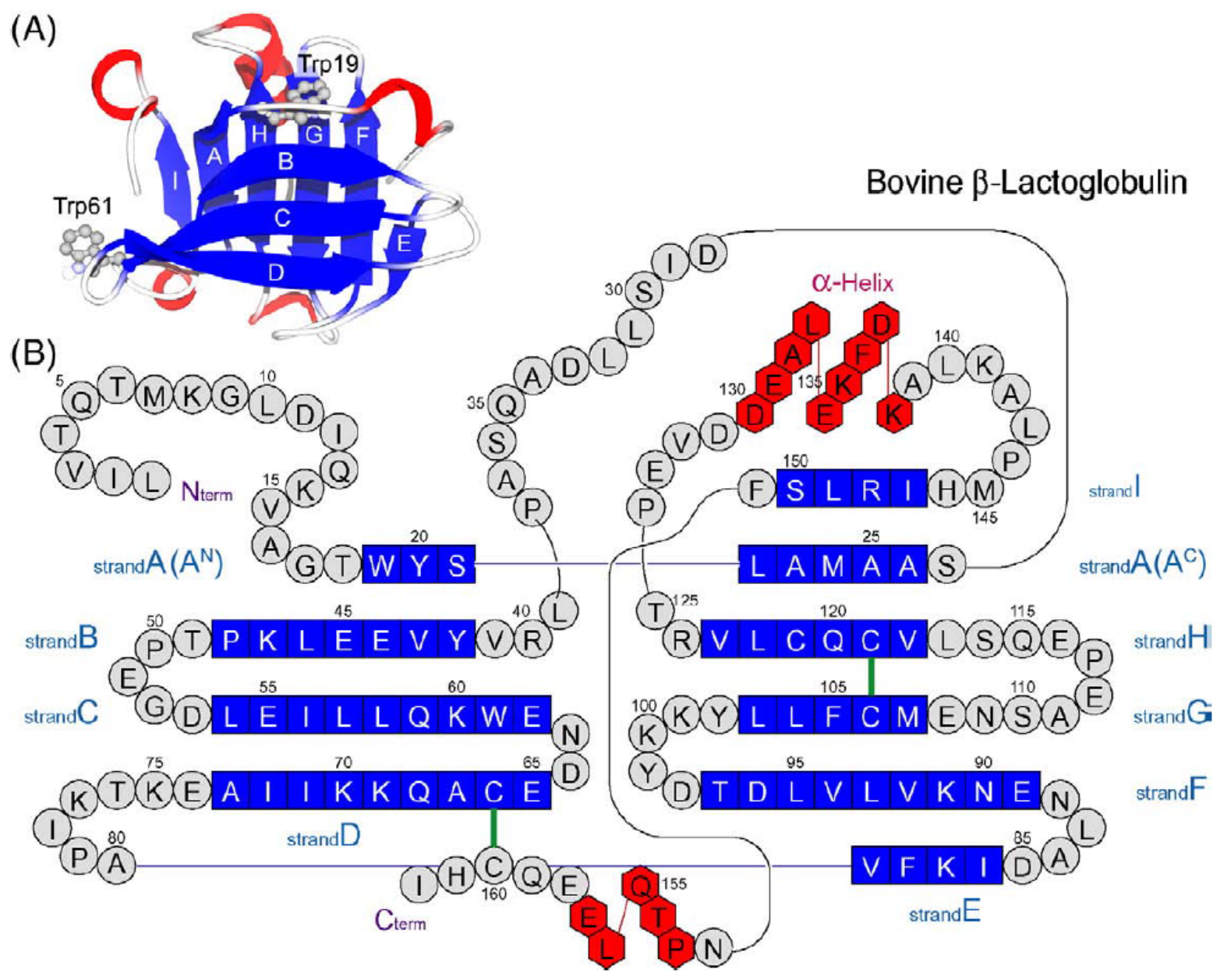

Fig. 3. The 3D structure and amino acid sequence of bovine BLG. (A) Ribbon diagram of a single subunit of bovine BLG lattice $X$, whose pdb code is 1BEB. The $\beta$-strands are labeled. Trp residues are represented as balls and sticks. The diagram was produced using the program MolFeat (FiatLux, Tokyo, Japan). (B) A schematic representation of the amino acid residues of the BLG sequence. Residues making up the $\alpha$-helix, $\beta$-sheet, and loop are represented by hexagons in red, squares in blue, and circles in grey, respectively. Green lines indicate the positions of disulfide bonds. It is seen that BLG has two $\beta$-sheets; The B-D strands and N-terminal half of the A strand (denoted AN) consist of one and the $\mathrm{E}-\mathrm{H}$ strands and $\mathrm{C}$-terminal half of the A strand (denoted $\mathrm{AC}$ ) consist of the other. (Sakurai et al. 2009) 


\section{Figure 4:}

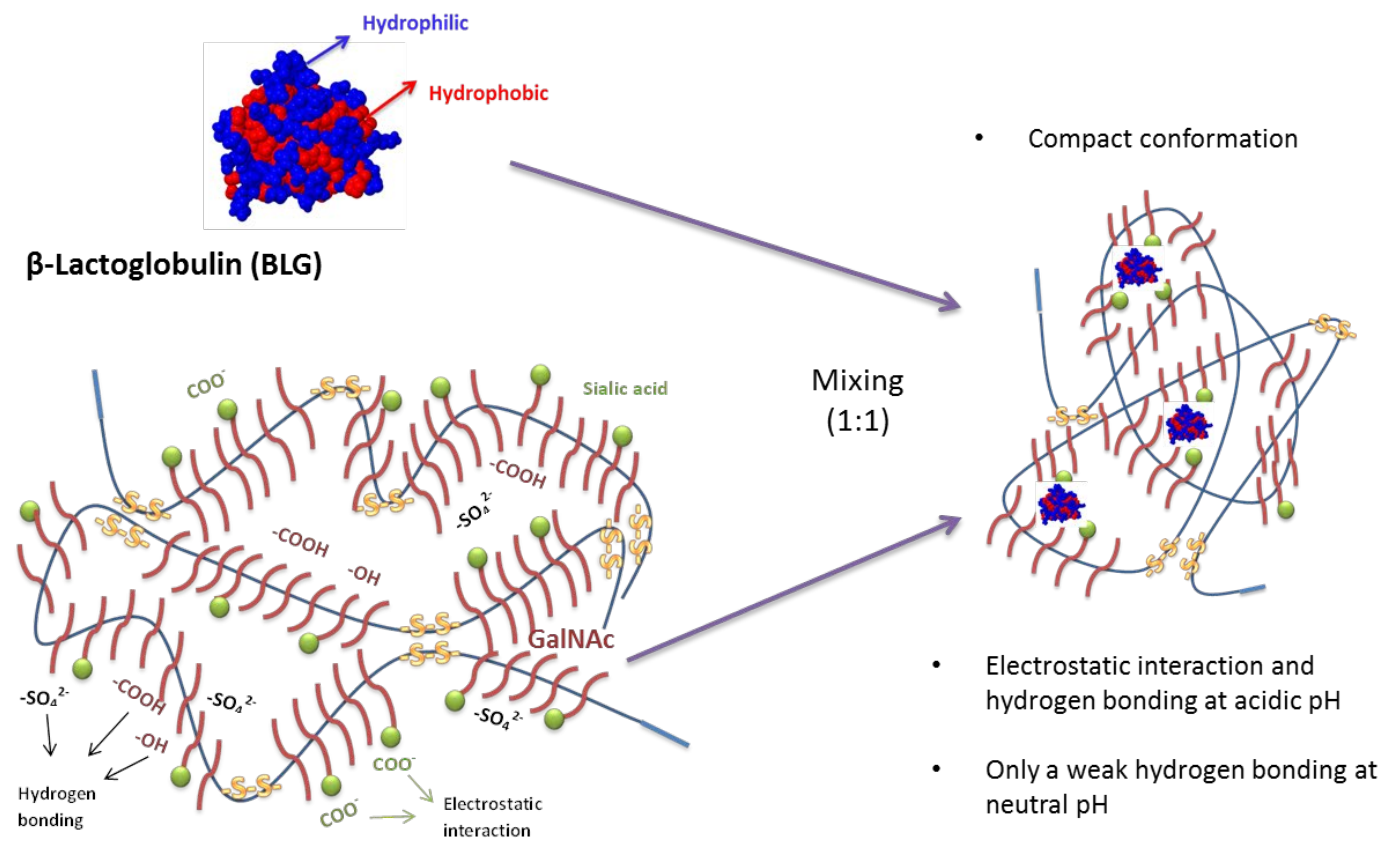

Bovine Submaxillary Mucin (BSM)

Fig. 4. Illustration of the interaction between $\beta$-lactoglobulin and bovine submaxillary mucin. (Çelebioğlu et al. 2015) 


\section{Figure 5:}

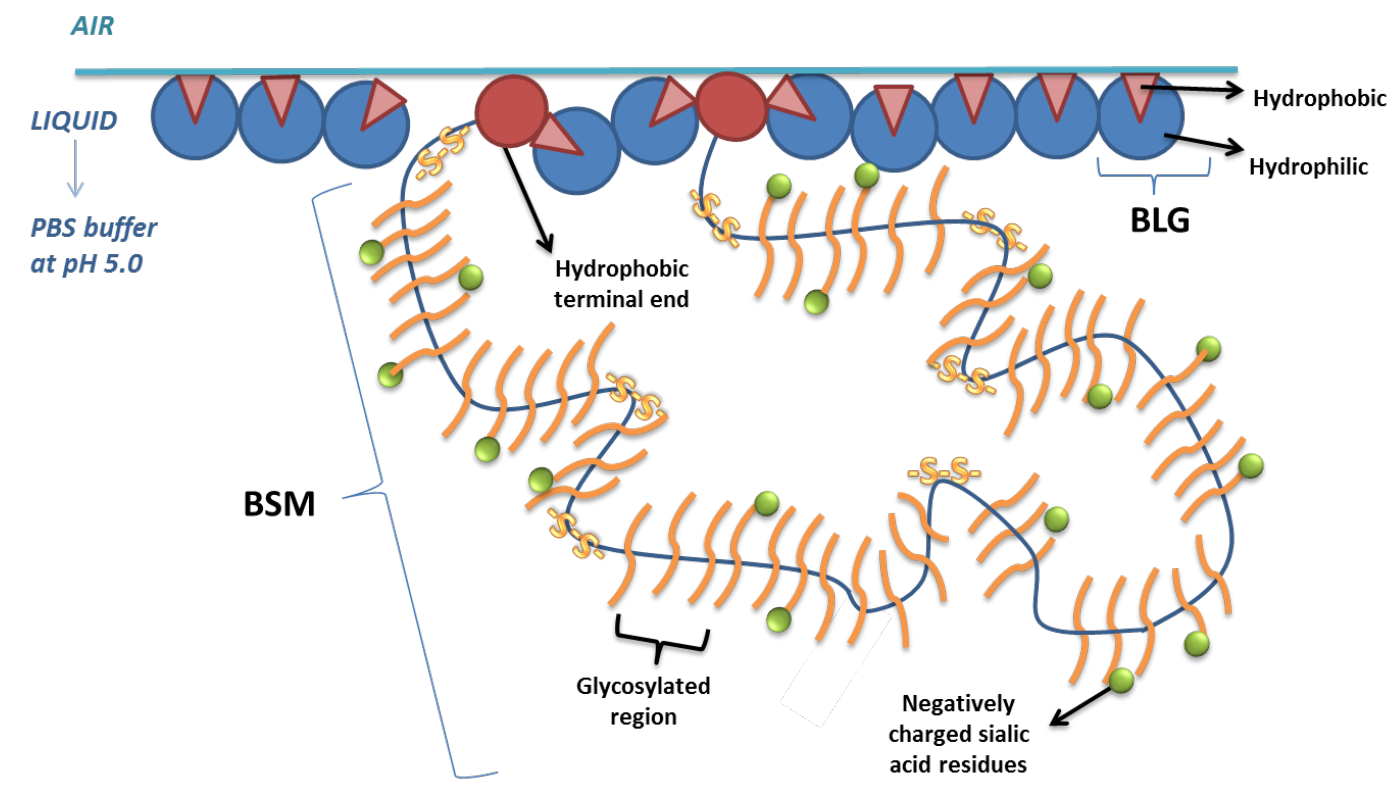

Fig. 5. Interfacial layer of BLG-BSM mixture showing the penetration of the hydrophobic parts of BSM between the adsorbed BLG molecules and disorder their cohesive assembly, which is most pronounced at pH 5. (Çelebioğlu et al. 2017) 
Figure 6:

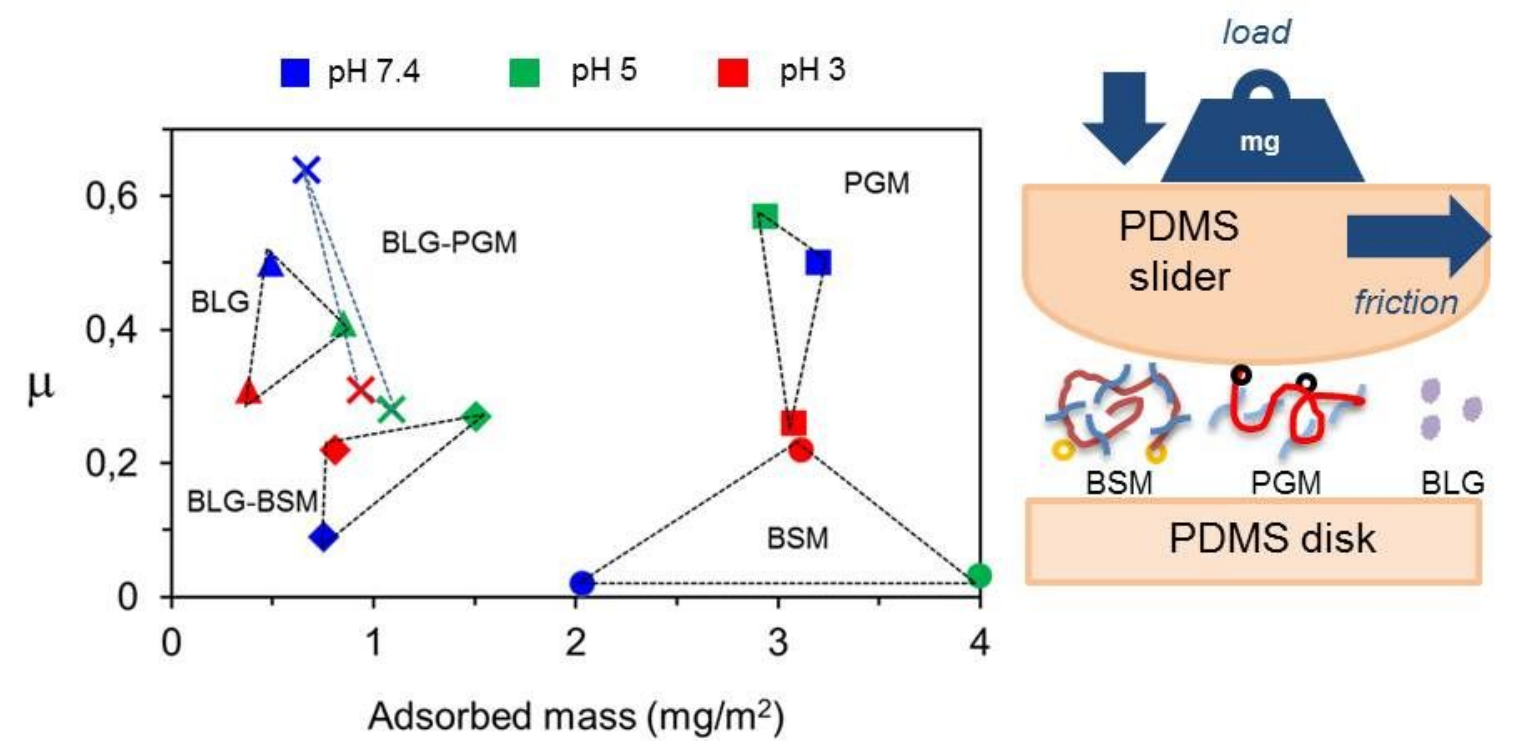

Fig. 6. (a) Coefficient of friction, $\mu$ (PDMS-PDMS pair) vs. adsorbed mass, $\Gamma$ (PDMS surface) of the protein solutions $(1 \mathrm{mg} / \mathrm{mL}$ concentrations only). The color codes are for different $\mathrm{pHs}$ : red for $\mathrm{pH}=3$, green for $\mathrm{pH}=5$, and blue for $\mathrm{pH}=7.4$. Different symbols represent different protein or mixed protein solutions. (For interpretation of the references to color in this figure legend, the reader is referred to the web version of this article. (Çelebioğlu et al. 2016)). (b) Schematic presentation of protein molecules under tribological stress using pin-on-disk tribometer with PDMS-PDMS tribopair. 


\section{Figure 7:}

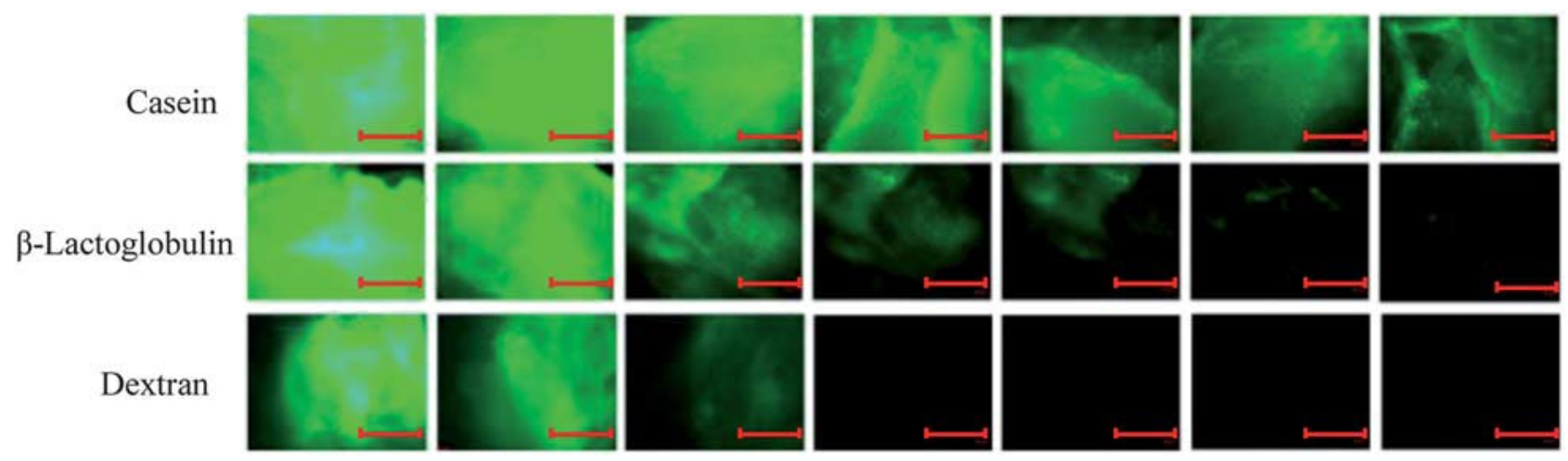

Fig. 7. Exemplary fluorescent microphotographs, showing the retention of casein, $\beta$-lactoglobulin and dextran on buccal mucosa against the number of washes with artificial saliva. Scale bars indicate $500 \mathrm{~mm}$ at image magnification (Wither et al. 2013) 


\section{Figure 8:}
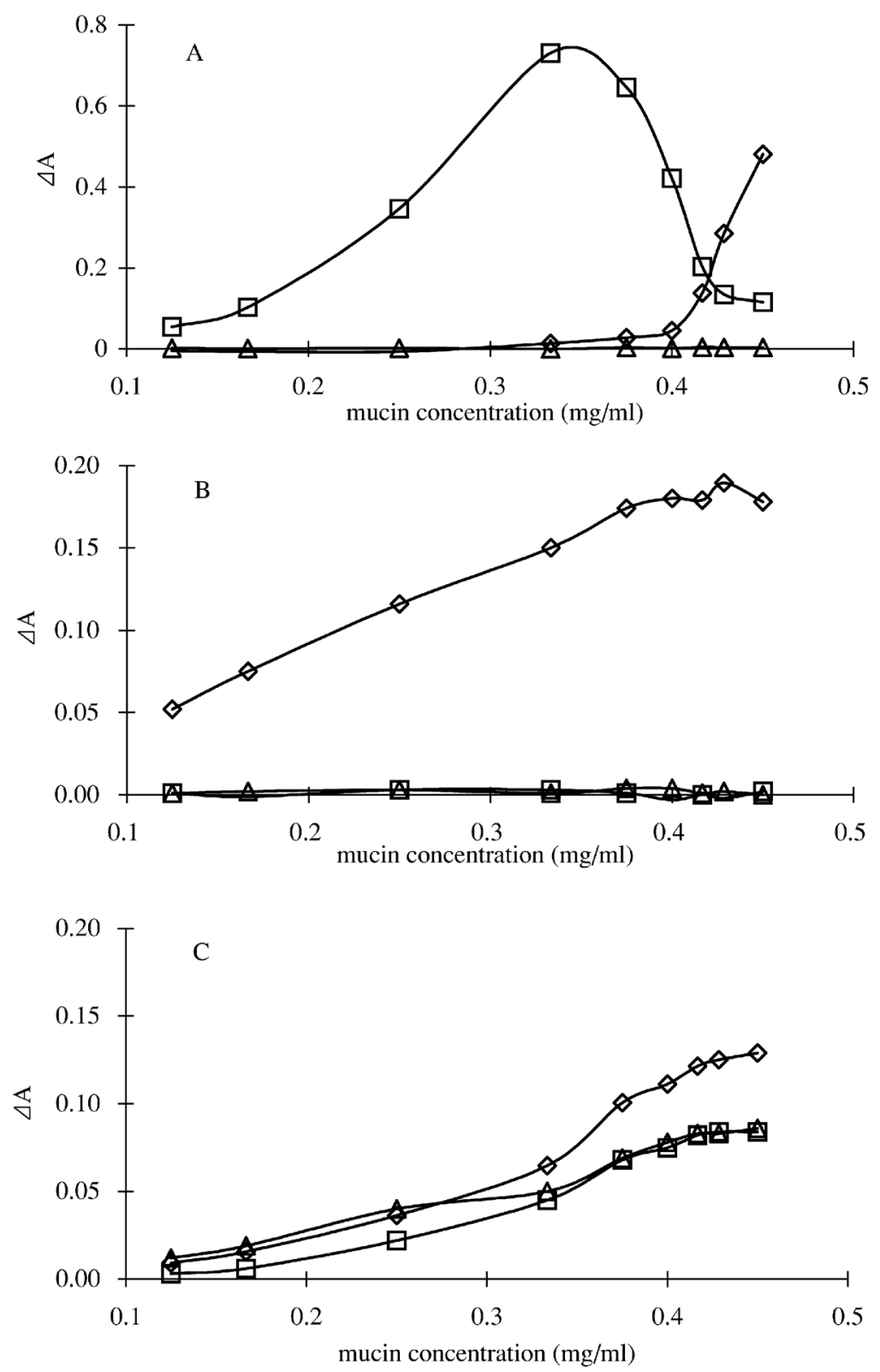

Fig. 8. Turbidimetric measurement of the interactions of gelatin and aminated gelatin with mucin (type III) in (A) purified water, (B) phosphate-buffered saline (PBS) and (C) simulated gastric fluid (SGF). Mucin solution $(0.5 \mathrm{mg} / \mathrm{ml})$ and gelatin solution $(1 \mathrm{mg} / \mathrm{ml})$ were mixed at volume ratios between $1: 3$ to $9: 1 . \Delta A$ represents the difference between the experimental and theoretical absorbances of the mixed solution. Each point represents the mean of three experiments. Key: $(\triangle)$ gelatin (IEP=5.0); $(\square)$ gelatin (IEP=9.0); $(\diamond$ aminated gelatin. (Wang et al. 2001) 
Figure 9:

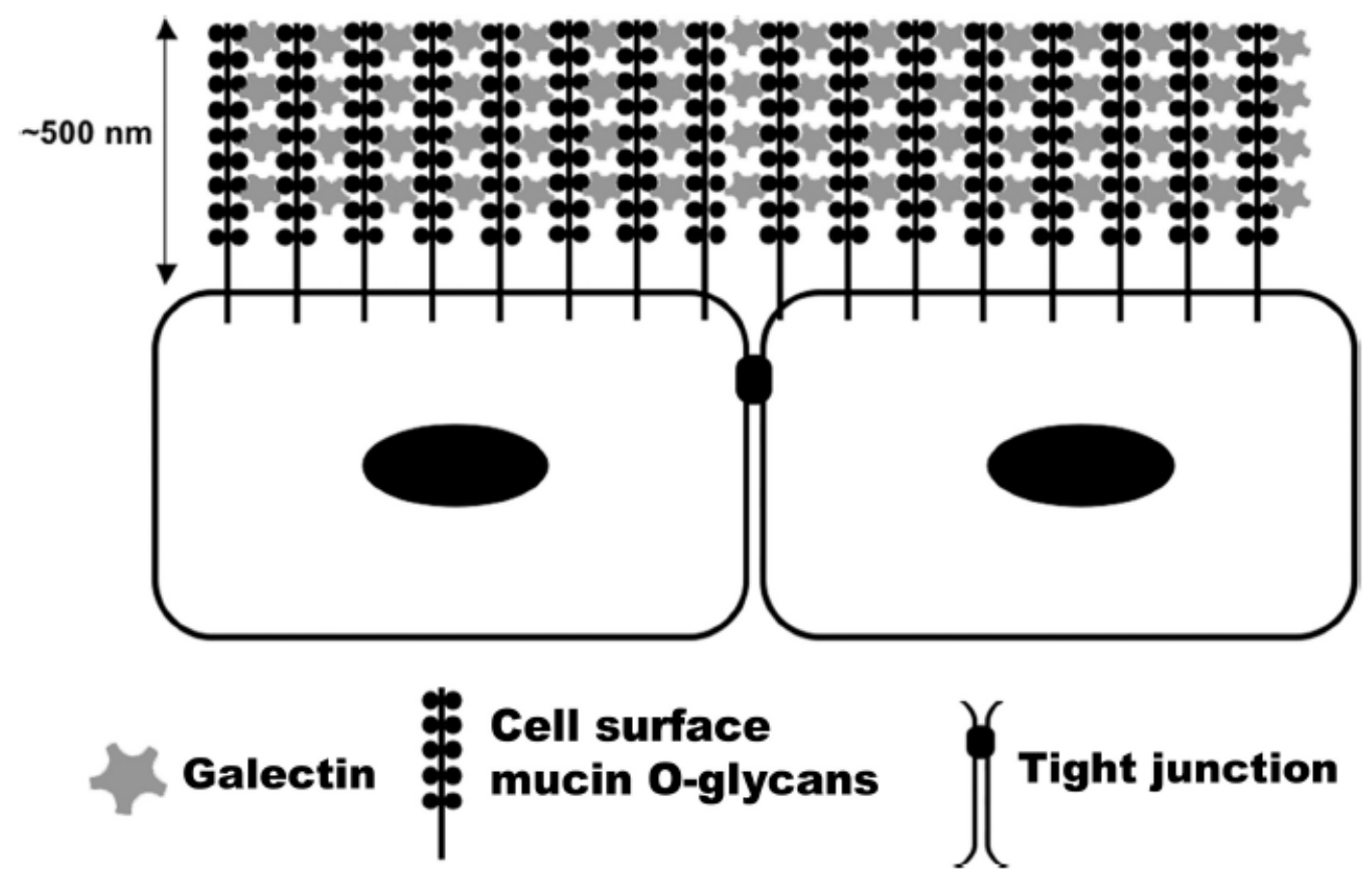

Fig. 9. Proposed model of galectin-mucin barrier formation on epithelial surfaces. (Argueso et al. 2009) 


\section{Figure 10:}
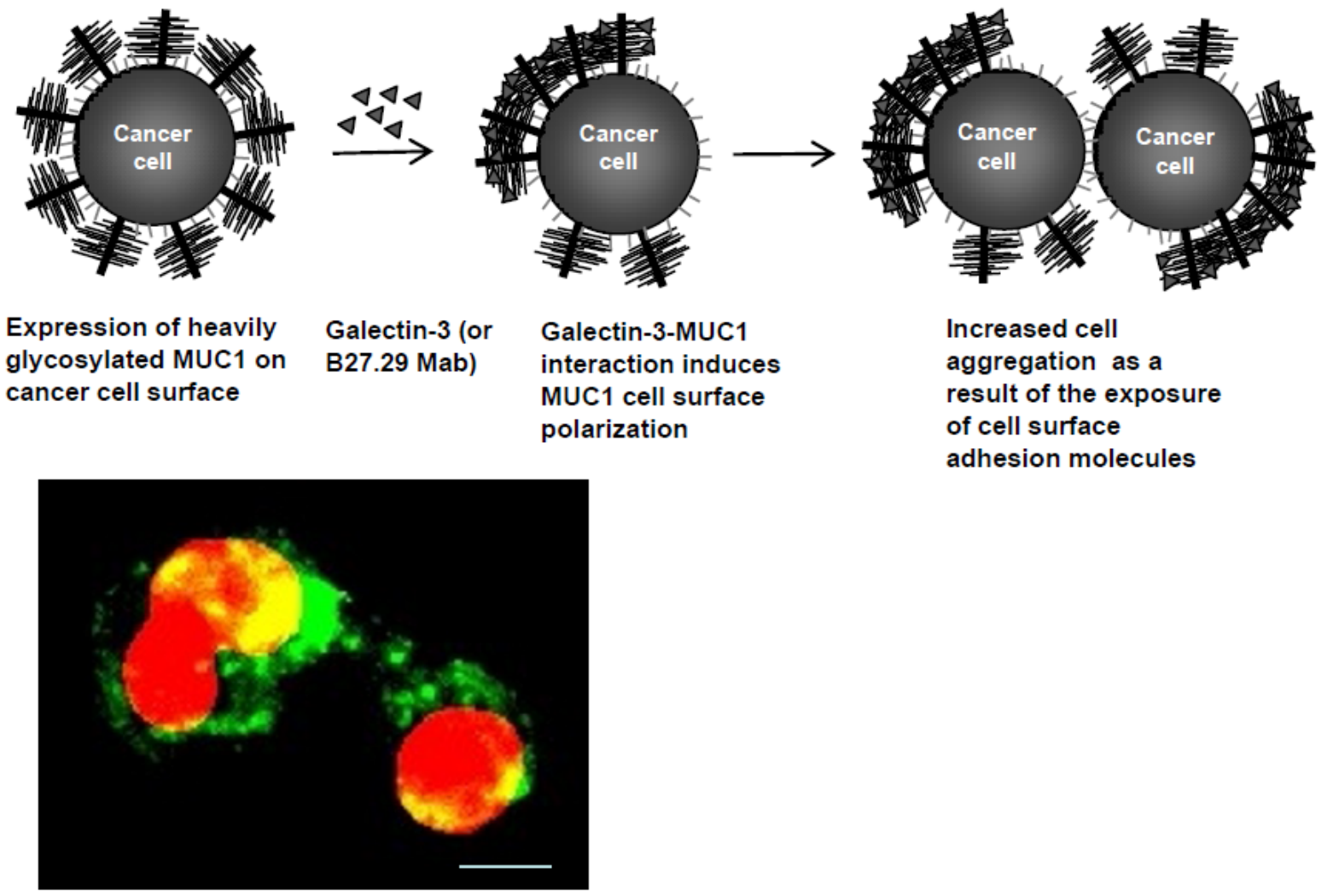

Fig. 10. Representative images of the MUC1 localization in cell aggregates are shown (top). Localization of the cell aggregates-associated MUC1 (green) after treatment of the cells with 1 $\mu \mathrm{g} / \mathrm{ml}$ galectin-3 for $48 \mathrm{hr}$ under suspension (red: cell nucleuses) (bottom). Bar $=10 \mu \mathrm{m}$. (Zhao et al. 2010) 